WSRC-TR- $-91-512$

DE92 015330

\title{
FINAL DESIGN REVIEW OF BORON CARBIDE SAFETY ROD (U)
}

by

\author{
R. N. Lutz
}

Westinghouse Savannah River Company

Savannah River Site

Aiken, South Carolina 29808

A Technical Report for publication

\section{DISCLAIMER}

\begin{abstract}
This report was prepared as an account of work sponsored by an agency of the United States Government. Neither the United States Government nor any agency thereof, nor any of their employees, makes any warranty, express or implied, or assumes any legal liability or responsibility for the accuracy, completeness, or usefulness of any information, apparatus, product, or process disclosed, or represents that its use would not infringe privately owned rights. Reference herein to any specific commercial product, process, or service by trade name, trademark, manufacturer, or otherwise does not necessarily constitute or imply its endo:sement, recommendation, or favoring by the United States Government or any agency thereof. The views and opinions of authors expressed herein do not necessarily state or reflect those of the United States Government or any agency thereof.
\end{abstract}

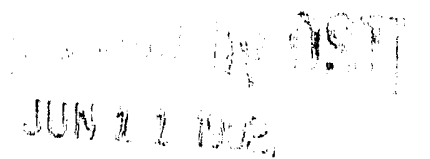

Whing

This report was prepared in connection with work done under Contract No. DE-AC09-89SR18035 with the U.S. Department of Energy. By acceptance of this paper, the publisher and/or recipient acknowledges the U.S. Government's right to retain a nonexclusive, royalty-free license in and to any copyright covering this paper, along with the right to reproduce and to authorize others to reproduce all or part of the copyrighted paper. 
WSRC-TR-91-512

\section{FINAL DESIGN REVIEW OF BORON CARBIDE SAFETY ROD (U)}

\section{Publication Date: September 24, 1991}

Patent Staws

This internal management report is being transmitted without DOE patent clearance, and no further dissemination or publications shall be made of the report without prior approval of the DOE-SR patent counsel.

Dozs not contan incLABBIFIED CONTROUL Minct AR INFORMATION

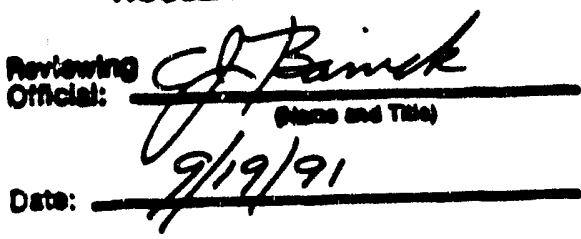

Westinghouse Savannah River Company Savannah River Site Aiken, SC 29808

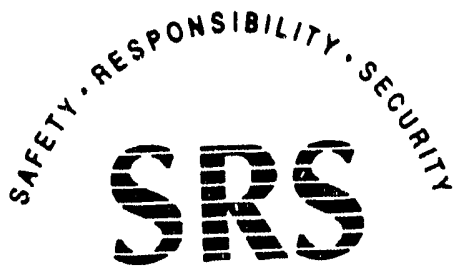




\section{DISCLAIMER}

This report was prepared by Westinghouse Savannah River Company (WSRC) for the United States Department of Energy under Contract No. DE-ACO9-88SR18035 and is an account of wort performed under that contract. Neither the United States Depertment of Energy, nor WSRC, nor any of their employees makes any warranty, expresced or implied, or assumes any legal liability or responsibility for the eccuracy, completeness, or usefuloess, of any information, apparabus, or product or process disclosed herein or represents that its use will not infringe privately owned rights. Reference berein to any specific commercial product, process, or service by tridemart, nume, manufecturer or otherwise does not necessarily constitute or imply endorsement, recommendation, or favoring of same by WSRC or by the United Staies Government or any agency thereof. The views and opinions of the authors expressed herein do not necessarily state or reflect those of the United States Government or any arency thereof. 
WSRC-TR-91.512

\section{RRTD}

REACTOR RESTAAT

TECHNICAL DIRECTOR

Keywords: Safety Rods

Gamma Heating

Loss of Coolant Accident

Retention - Permanent

\section{FINAL DESIGN REVIEW \\ OF BORON CARBIDE SAFETY ROD (U)}

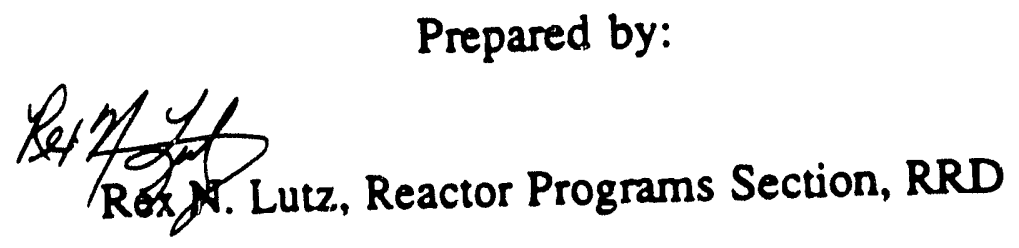

Issued: September 1991

SRS WESTINGHOUSE SAVANNAH RIVER COMPANY Savannah River Site Aiken, SC 29808

Prepared for the U. S. Department of Energy under Contract DE-AC09-89SR18035 
DOCUMENT: WSRC-TR-91-512

TITLE: FINAL DESIGN REVIEW OF BORON CARBIDE SAFETY ROD (U)

DATE: September 1991

\section{APPROVAL}

A.7.m C farlane $9 / 18 / 91$
$\begin{aligned} & \text { A. F. McFarlane, Manager } \\ & \text { Reactor Programs }\end{aligned}$

\section{COMMUTTEE MEMBERS}
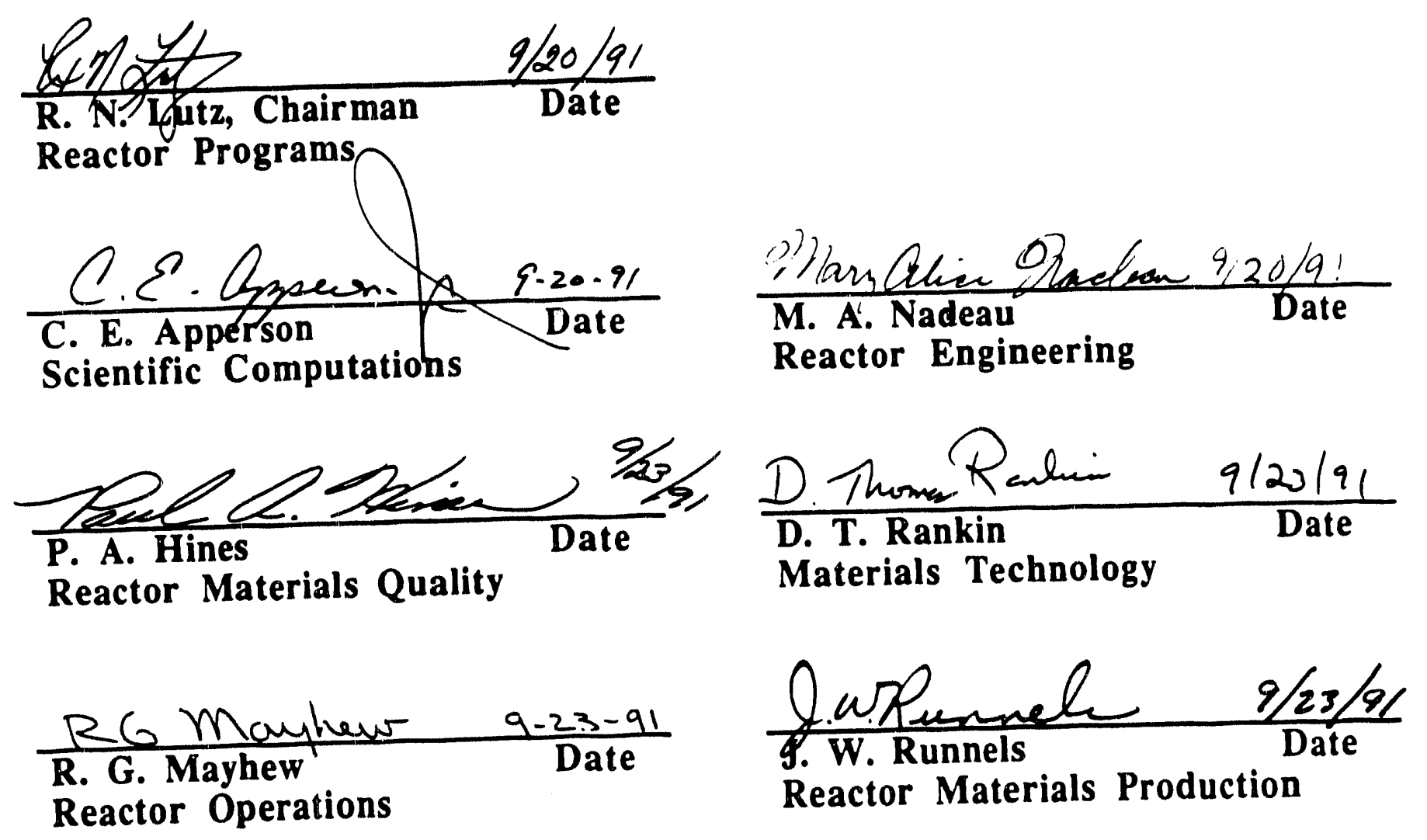


\section{TABLE OF CONTENTS}

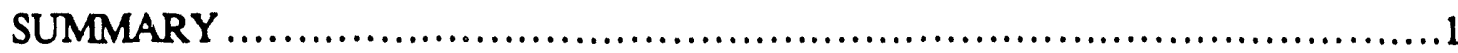

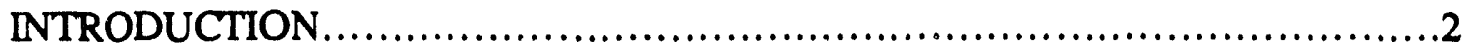

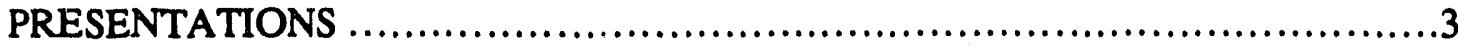

MTS Testing Program.......................................................

EES Testing Program .....................................................4

Reactor Materials Production Readiness ......................................5

General Discussion ............................................................5

Committee Discussion...................................................6

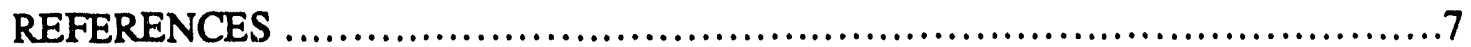

APPENDIX A

APPENDIX B

APPENDIX C 


\section{FINAL DESIGN REVIEW OF BORON CARBIDE SAFETY ROD}

\section{SUMMARY}

The Final Design Review meeting was held August 30, 1991 to evaluate the status of the design program for the boron carbide safety rod. Meeting attendance is provided as Appendix A. The objectives of the meeting were:

1. Review the results of the boron carbide safety rod testing program.

2. Identify any reasons to extend the fabrication hold put in place following the delivery of the test rods.

3. Determine what additional work is necessary.

4. Make appropriate recommendations to WSRC management.

This report has been prepared to meet the intent of existing and draft Reactor Restart Division requirements. Following the review, a memorandum was issued (RRD-PSI910073) to accomplish prompt notification of WSRC management.

The Committee reviewed information presented by representatives of Savannah River Laboratory (SRL) Equipment Engineering Section (EES), SRL Materials Technology Section (MTS) and Reactor Materials Engineering and Technology (RMET). The meeting agenda is provided as Appendix B.

This Design Review Committee concluded that the production hold established following the Interim Design Review should be released, allowing the full production run to begin September 3, 1991. There is no anticipated change to the design as a result of further confirmatory testing.

The Committee also made the following recommendations:

1. The thermal gradient across the boron carbide pellets in a rod left in core during power operations should be calculated. The potential for thermal stress induced cracking should be assessed.

2. The potential impacts of boron carbide relocation due to pellet damage should be evaluated, especially with respect to pellet height in the rod.

3. The interior surfaces of the vibration test rods should be examined, following completion of testing, for indications of abrasion or wear caused by the pellets.

4. It should be demonstrated that there are no significant effects on the safety rod resulting from the serial combination of vibration and insertion.

5. The production procedures should include provisions to 1) ensure that the axial loading spring is dimensionally correct prior to use and 2) specify the actions required if mishandling occurs during the production process.

Responsibilities for follow-up on these recommendations have been assigned. MTS will address recommendations 1 and 2, EES will address recommendations 3 and 4, and RMP will address recommendation 5. RP will issue requests for task scope modifications where required. 
It has been the objective of the design process to meet or exceed these criteria, identifying and addressing any additional concerns, and design a replacement safety rod that functions as desired. A Preliminary Design Review was held May 16, 1991, and is documented in Reference 1. An Interim Design Review was held July 9, 1991, and is documented in Reference 2. The design was fixed following that review, and test units were fabricated and tested prior to the Final Design Review.

\section{PRESENTATIONS}

The speakers' presentations are summarized in the order of appearance at the review. Copies of presentation materials are provided in Appendix C.

\section{MTS Testing Program}

N. J. Iyer, Materials Technology Section (MTS), summarized the results of the MTS testing and analyses. The MTS program includes eight analyses and tests, described in References 3 and 4. An interim report (Reference 5) provides details of the work accomplished at the time of the design review.

The MT'S analytical and experimental results provide confidence that, for both normal and abnormal operating conditions, the design of the boron carbide safety rod is acceptable.

Irradiation response of the materials comprising the rod indicate that helium generation during the five year design life is negligible. In the event of gamma heating of these rods to $1000^{\circ} \mathrm{C}$, rod integrity will not be lost due to internal pressurization. In the event that a rod were to be irradiated, left in the core at $50 \%$ power, for one month, neither helium pressurization nor the pellet swelling will result in a challenge to the rupture strength of the sheath.

Boron carbide is compatible with stainless steel at temperatures less than $700^{\circ} \mathrm{C}$. At $1000^{\circ} \mathrm{C}$, cladding penetration by chemical attack as a result of the interaction between boron carbide and the steel would require several hundred hours. There is no degradation of boron carbide pellets exposed to moderator.

Corrosion susceptibility of the boron carbide rods is precluded by the moisture and purity specifications of the pellets. All steel parts other than the 302 SS spring are corrosion evaluated $304 \mathrm{~L}$ stainless. The pellet moisture acceptance criterion is $<750 \mathrm{ppm}$ in assembled rods. Moisture testing of pellets indicates that, due to pellet density and particle size, the fabricated pellets moisture content plateaus at about $250 \mathrm{ppm}$ when exposed to $100 \%$ humidity. The average moisture content of pellets removed from one of the test rods was $120 \mathrm{ppm}$.

Calculations of the safety rod dynamic behavior during scram scenarios focused upon the worst case; mechanical snubbing with no electrical snubbing. The damping effects of fluid resistance and reactor superstructure were not considered. It was calculated that, for these conservative assumptions, the bottom end fitting would be subjected to an impact loading of 6000 pounds. RMP provided roll joint specimens for testing during development of the technique used in fabrication. Those roll joints were pull tested to failure in the 7000 to 10,000 pound range. Additionally, EES drop tested three rods on mechanical snubbers, in air, with no roll joint failures. See the EES summary for more information. 
WSRC-TR-91-512

September 1991

Concerns regarding the sensitivity of these rods to mishandling have been addressed through controlled flexibility, bowing response and mishandling tests. The rod is approximately $60 \%$ as stiff as the cadmium safety rod. Two person handling, supporting the rod at the ends only, caused no damage to pellets or the rod geometry. One person handling resulted in rod deformation.

Thermal response tests of a shortened version of the safety rod that maintained the gas/volume ratio of the full scale rod were successful. The rod was radiographed and dimensionally measured prior to testing. The unit was then subjected to three separate tests, each prototypic of a postulated gamma heating event, at 600,800 , and $1000^{\circ} \mathrm{C}$. Temperature and internal pressure data were recorded during the testing. Measurements and radiographs indicated no damage to the safety rod following these tests.

\section{EES Testing Program}

M. D. McKay, the task leader for the Equipment Engineering Section (EES) safety rod program, presented the results of testing completed at the time of the design review. The EES program consists of three sets of tests, described in References 6 and 7.

The first EES tests discussed involved verifying that the design rod would function mechanically in an acceptable manner, experiencing no hang ups and scramming rapidly enough. For comparative purposes, both a cadmium rod from spares and a test rod were scrammed with electrical snubbing into a water filled tank. EES reported that there was no observable dynamic behavior difference between the two rod types. The elapsed time between applying the trip signal until the electrical snubbing voltage was applied to the clutch was observed to be 0.01 second longer for the boron carbide rod thain the cadmium rod. At the onset of electrical snubbing, the rods were seven to eight feet into the tank. The boron carbide rod travel time from trip signal applied to fully inserted was reported as 0.2 second longer. Neither rod type experienced any partial insertions during testing.

EES conducted drop tests of three test rods to examine damage characteristics. Two test series were run, nne with electrical snubbing and the other with mechanical snubbing only. These drop tests were in air, to be more conservative and more likely to induce pellet or rod damage. In the first series, each rod was radiographed prior to testing, scrammed in air with electrical snubbing once, re-radiographed, and scrammed 25 additional times. No damage to the pellet columns or rods was caused by these drop tests. One rod experienced a latch failure and subsequent mechanical snubbing. That rod was radiographed before further testing; one boron carbide pellet was found, through very close examination of the filrns, to have been chipped very slightly. The rod was returned to the electrical snubbing tests and suffered no additional damage.

The same three rods drop tested with electrical snubbing were then scrammed in air with mechanical snubbing only. As discussed in the MTS presentation, large impact loading was calculated for mechanical snubbed insertions. Although mechanical snubbing occurs infrequently in reactor operations, it was of concern that the rod behavior be understood and acceptable when it happens. After each drop, the rods were radiographed and the snubber replaced. Two rods were mechanically snubbed only twice, the third was mechanically snubbed five times. The average number of pellets damaged in any way - chipped, cracked or broken following two drops was 10 (of 104). As expected, the number of pellets damaged increased with the number of mechanically snubbed insertions. Appendix C, 
Item 3, contains a graph that illustrates the progressive accumulation of boron carbide pellet damage in the one rod subjected to five mechanically snubbed drops in air. Rod disassembly and examination revealed that a total of 58 pellets were chipped and 10 were cracked or broken. In no instance was the integrity of the rod compromised; there was no failure of the roll joints that secure the end fittings. Mechanically snubbed insertions in water are expected to result in even less pellet damage due to the damping effect of the liquid.

In order to test the design for impact on the safety rod thimble and cup, a vibration test was developed by EES. Current one-inch thimble service life is three years, based on operating history of thimble failures in safety rod and other one-inch positions. This test was performed in lieu of full scale prototypic flow testing, facilities for which do not exist at SRS. The exact flow velocity distributions for all flow conditions and all one-inch positions cannot be mocked up outside of the reactor tank.

The vibration testing involved installing thimbles and cups in the 305-A mock $u_{r}$ ank, in which a cadmium rod and a boron carbide rod were mechanically vibrated over a range of low amplitude frequencies $(0.5-5 \mathrm{~Hz})$ for 16 hours. The rods, thimbles and cups were examined for wear; no measurable wear was found. The interior surface of the boron carbide rod had not yet been examined for wear of the stainless steel by the harder boron carbide pellets.

\section{Reactor Materials Production Readiness}

L. D. Dollar, RMET, discussed the 300 Area production readiness. Experience gained during the production of the test rods has been proceduralized to improve the quality of the final product. Improvement areas include counterbore depth control, cleaning, spring compression verification, evacuation and helium backfilling, and roll joint positioning.

The consultants questioned the completeness of the spring compression verification, and recommended adding the recording of verification that each spring used was dimensionally correct prior to rod assembly.

All 304L stainless steel parts will be corrosion evaluated (CE) material. A drawing revision was necessary to specify exclusive use of $3 / 4$ inch tubing for the long spacer in the inactive region of the rod, because CE piping was not available.

The production run schedule assumed September 3 as a start date. Given that start date, the fabrication, certification, and shipment of 80 rods will be completed by October 7, 1991 .

\section{General Discussion}

N. P. Baumann, SCS, was asked to explain the status of Nuclear Test Gauge (NTG) specifications and calibration. Reference 8 documents the SCS work on this topic.

Rod worths will be checked in the 300 Area using the Nuclear"?est Gauge. A standard rod was fabricated for use with the NTG under the Request for Product (Test Rods) written by Reactor Programs. The test rods that were run through the NTG possessed nuclear characteristics well within the specifications. The NTG procedures and equipment necessary to support full production of safety rods are ready. 
WSRC-TR-91-512

September 1991

\section{Committec Discussion}

The Committee discussion followed, resulting in the recommendations and observations provided in the Summary section of this report. The consultants were present and participated. The Committee was verbally polled and unanimously agreed that the boron carbide safety rod full production run should proceed. 


\section{REFERENCES}

1. R. N. Lutz, Preliminary Design Review of Proposed Safety Rod (U). WSRC-TR-91-426, Savannah River Site, Aiken, SC 29802 (July 1991).

2. R. N. Lutz, Interim Design Review of Boron Carbide Safety Rod (U). WSRC-TR-91-438, Savannah River Site, Aiken, SC 29802 (July 30, 1991).

3. Materials and Mechanical Design Analysis of Boron Carbide Reactor Safety Rods Task Plan (U), Task Number 91-047-1, (June 17, 1991).

4. Materials and Mechanical Design Analysis of Boron Carbide Reactor Safety Rods Task Quality Assurance Plan (U), Task Number 91-047-1, (June 17, 1991).

5. J. M. Marra, Materials and Mechanical Design Analyses of Boron Carbide Reactor Safety Rods, Interim Report, SRL-MTS-914036. (To be issued in September 1991).

6. Equipment Engineering Section Task Technical Plan 22053 - TTP Rev. 0.

7. Equipment Engineering Section Task Quality Assurance Plan 22053 - TQAP Rev. 0.

8. N. P. Baumann, Substitute Safety Rods .- Physics Design and NTG Calibration (U), WSRC-TR-91-427, Savannah River Site, Aiken, SC 29802 (July 1991).

9. M. R. Louthan et al., memorandum to J. D. Spencer, "Anticipated Behavior of Safety Rods During a Post LOCA Thermal Excursion," SRL-MTS-910177, September 12, 1991. 


\section{APPENDIX A}

Safety Rod Final Design Review Attendance

Committee:

$\begin{array}{ll}\text { R. N. Lutz } & \text { RP } \\ \text { C. E. Apperson } & \text { SCS } \\ \text { P. A. Hines } & \text { RMQ } \\ \text { R. G. Mayhew } & \text { ROD } \\ \text { M. A. Nadeau } & \text { RE } \\ \text { L. T. Rankin } & \text { MTS } \\ \text { J. W. Runnels } & \text { RMP }\end{array}$

Others:

$\begin{array}{ll}\text { J. J. Banks } & \text { RE } \\ \text { N. P. Baumann } & \text { SCS } \\ \text { L. D. Dollar } & \text { RMET } \\ \text { M. J. Donohue } & \text { RMET } \\ \text { T. C. Easterling } & \text { SRL/SARM } \\ \text { T. M. Fleck } & \text { RMET } \\ \text { H. Garkisch } & \text { WAESD } \\ \text { N. T. Hightower } & \text { SRL/SARM } \\ \text { B. Howard } & \text { EES } \\ \text { N. J. Iyer } & \text { MTS } \\ \text { D. R. Leader } & \text { MTS } \\ \text { M. D. McKay } & \text { EES } \\ \text { C. E. Morgan, Jr., } & \text { SAG } \\ \text { J. M. Morrison } & \text { RP } \\ \text { I. K. Paik } & \text { SAG } \\ \text { K. L. Planz } & \text { RMET } \\ \text { K. Radford } & \text { WSTC } \\ \text { M. Rosser } & \text { RE } \\ \text { E. R. Selden } & \text { RMET } \\ \text { M. K. Stewart } & \text { RMQ } \\ \text { W. Stubbs } & \text { DOE/SRSPO } \\ \text { D. A. Walkowiak } & \text { SAG } \\ \text { W. W. F. Yau } & \text { SRL }\end{array}$




\section{APPENDIK B}

\section{BORON CARBIDE SAFETY ROD DESIGN REVIEW AUGUST 30, 1991 \\ AGENDA}

0830

0930

1030

1100

1130
MTS Analytical and Testing Results

EES Testing Results

Production Readiness

A.dditional Items

Committee Discussion
N. Iyer

M. McKay

L. Dollar

As Required 


\section{CONTENTS}

1. $\quad$ L. D. Dollar, Slide Package, "Reactor Materials Production Readiness."

2. N. C. Iyer, Slide Package, "Materials \& Mechanical Design Analysis of Boron Carbide Safety Rods."

3. M. D. McKay, et al., Slide Package, "EES Testing of the Boron Carbide Safety Rods." 


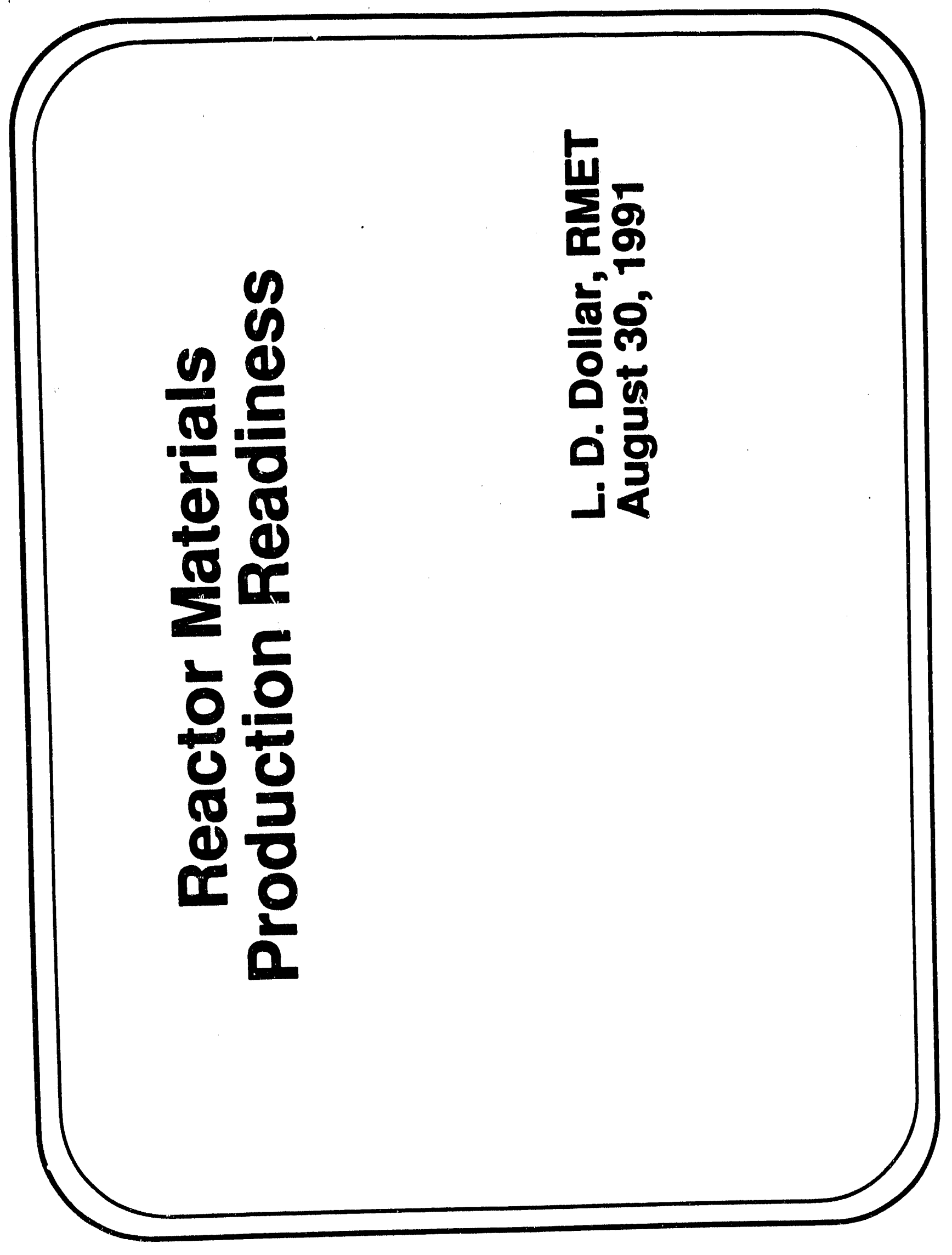




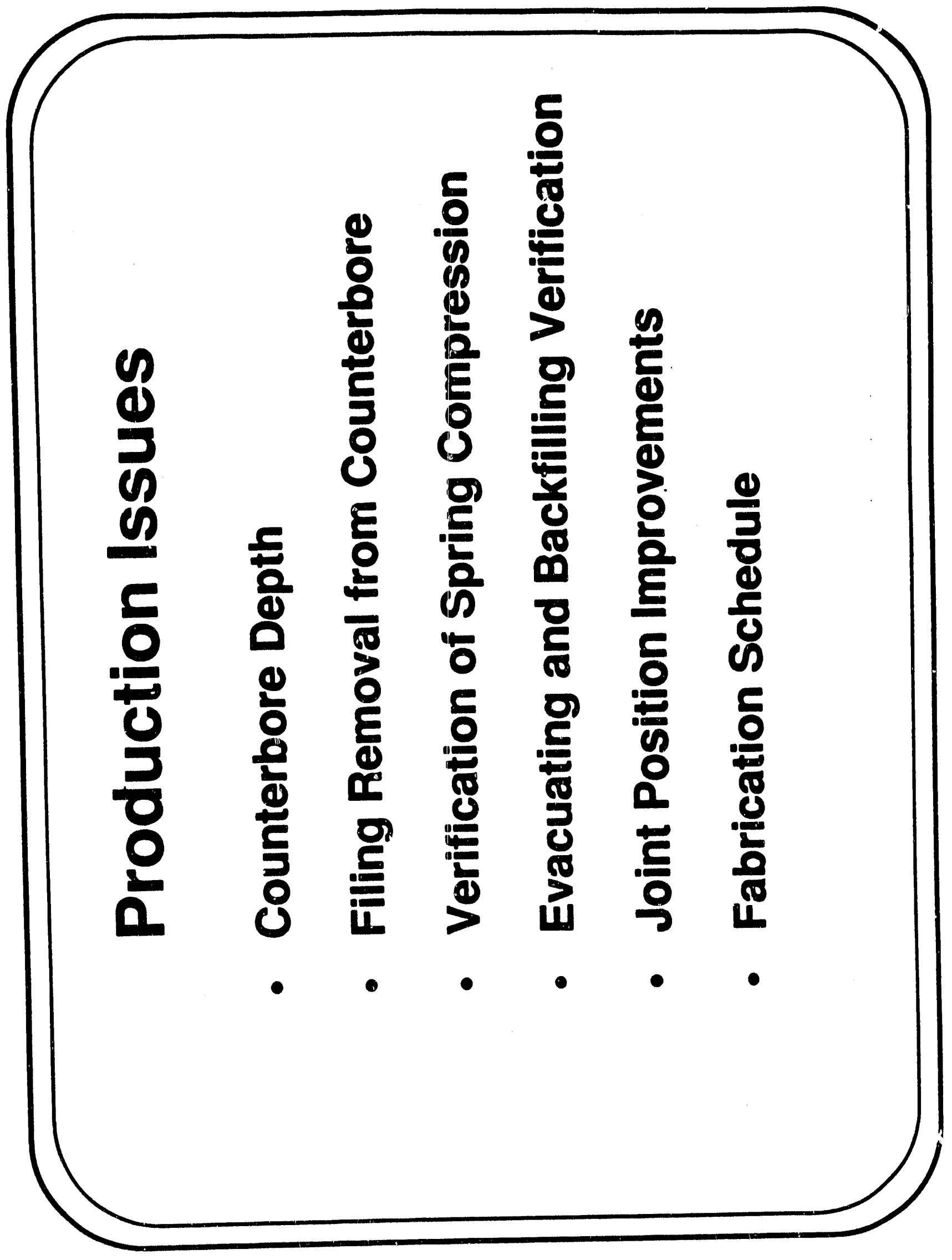




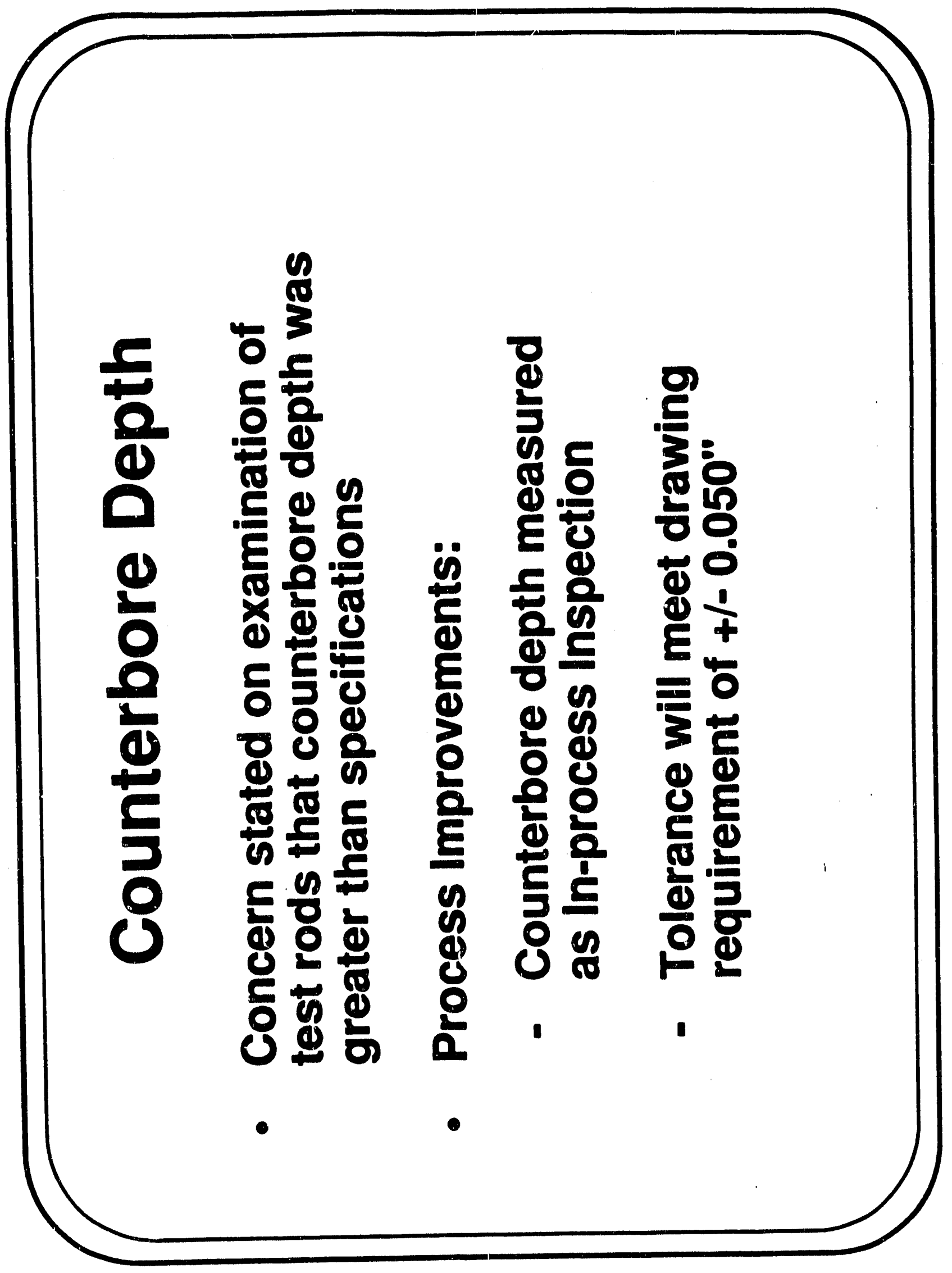




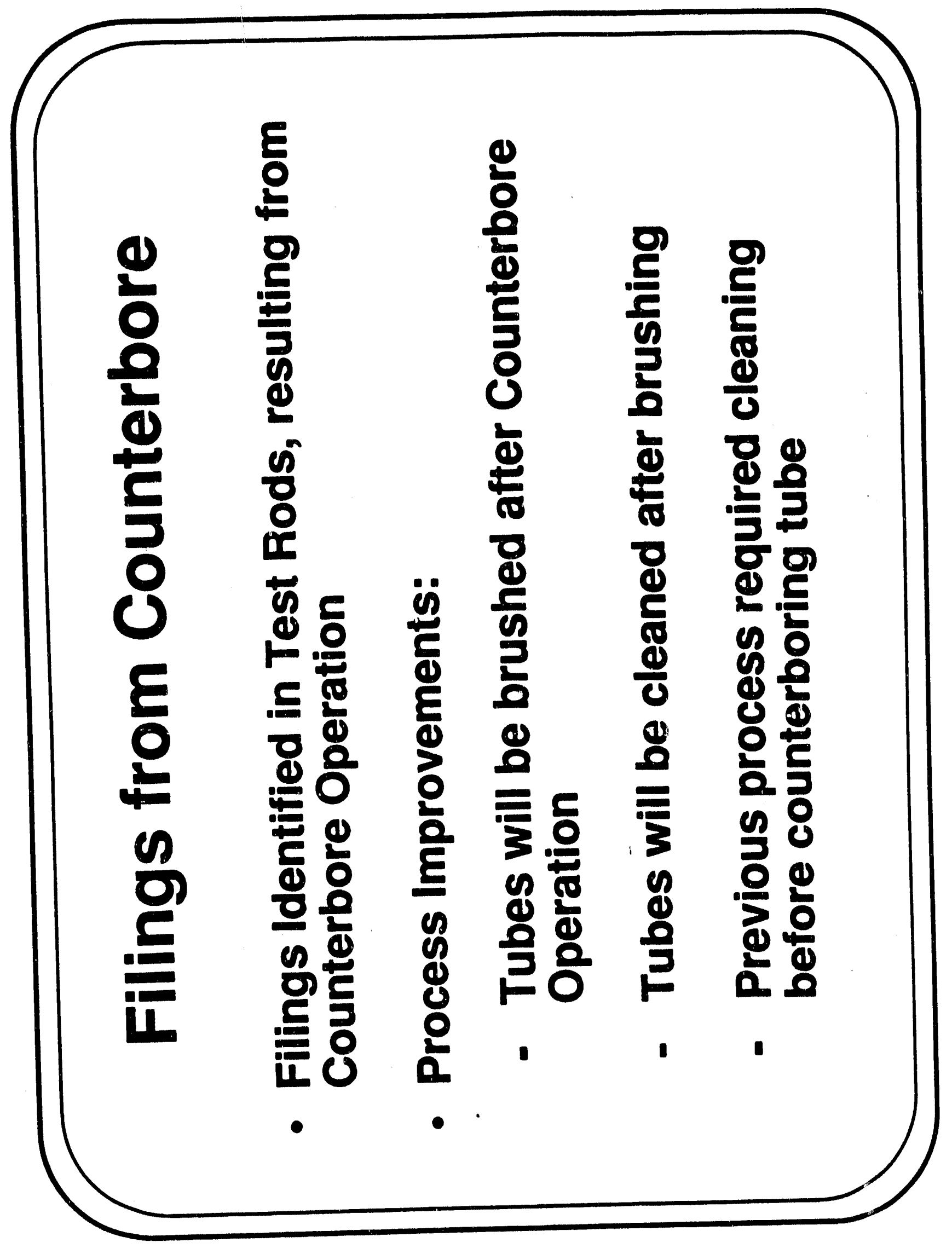




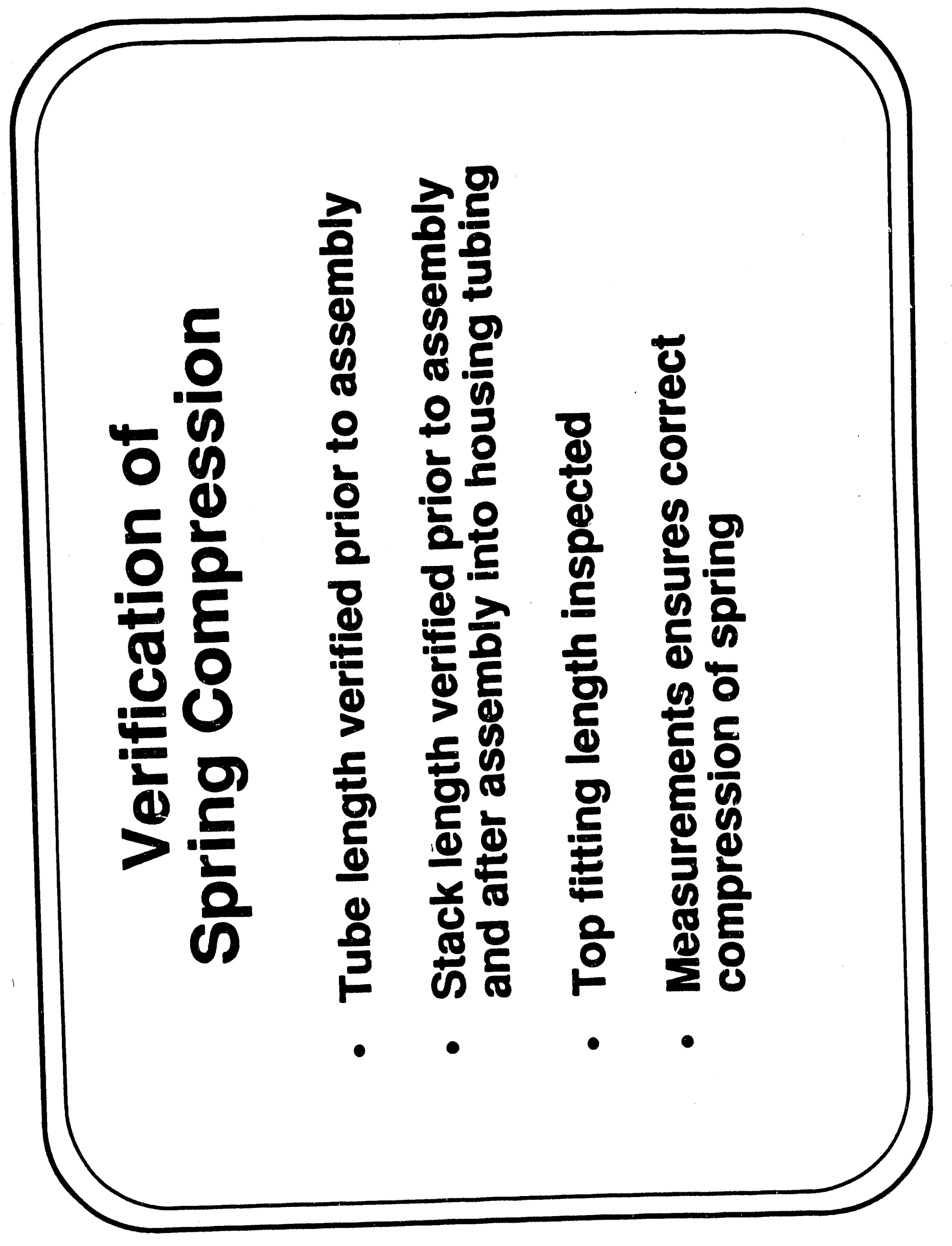




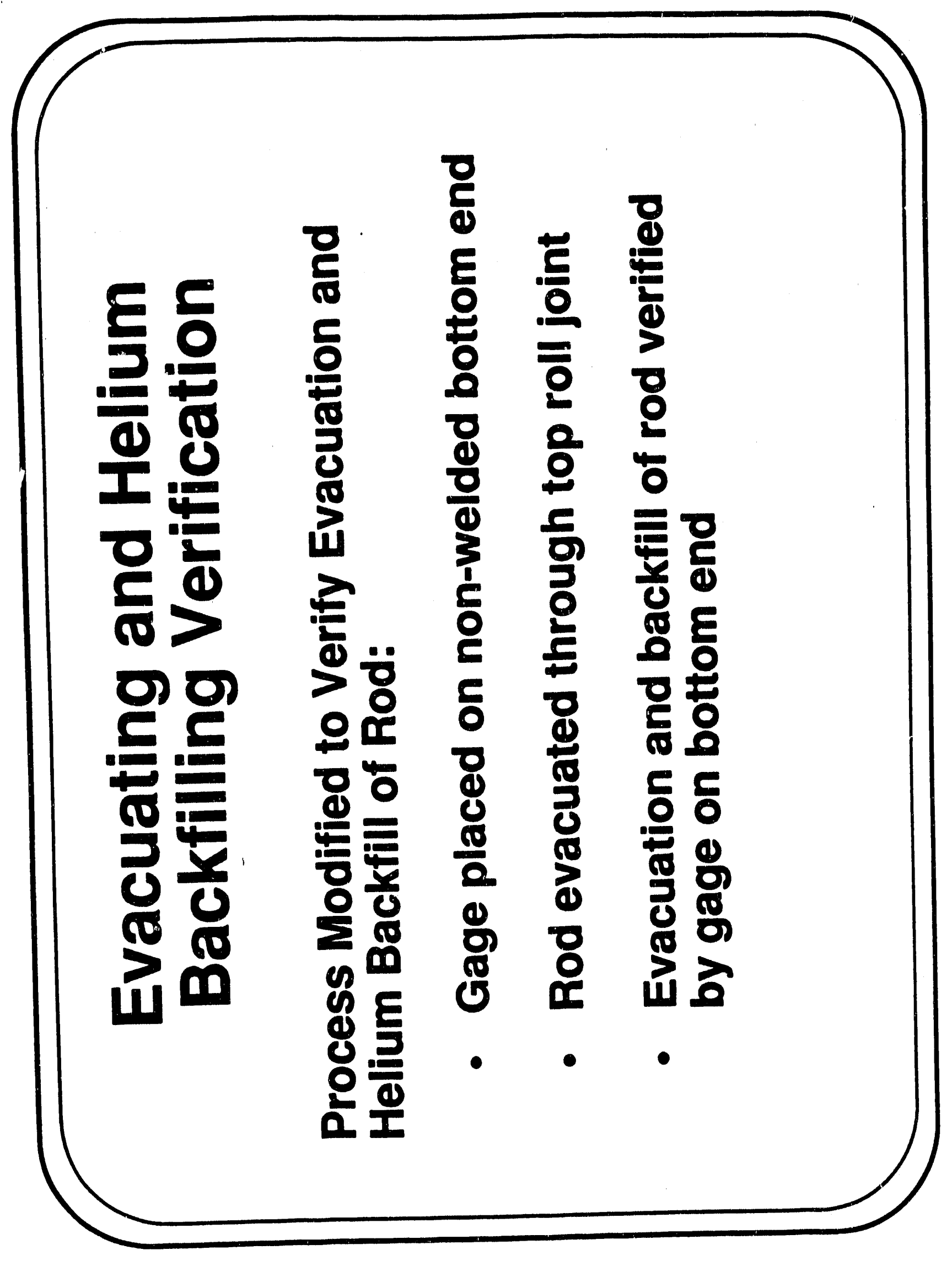




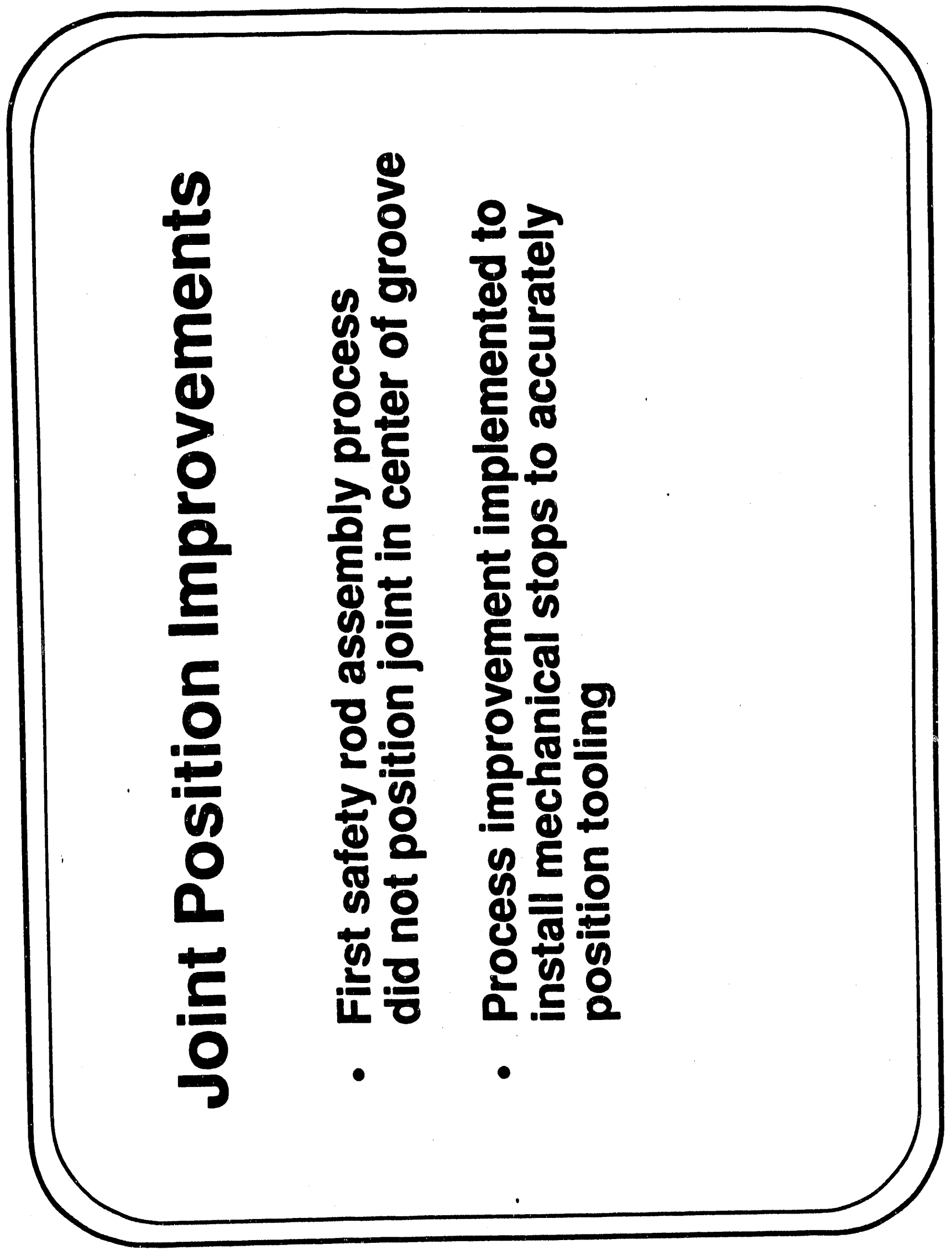




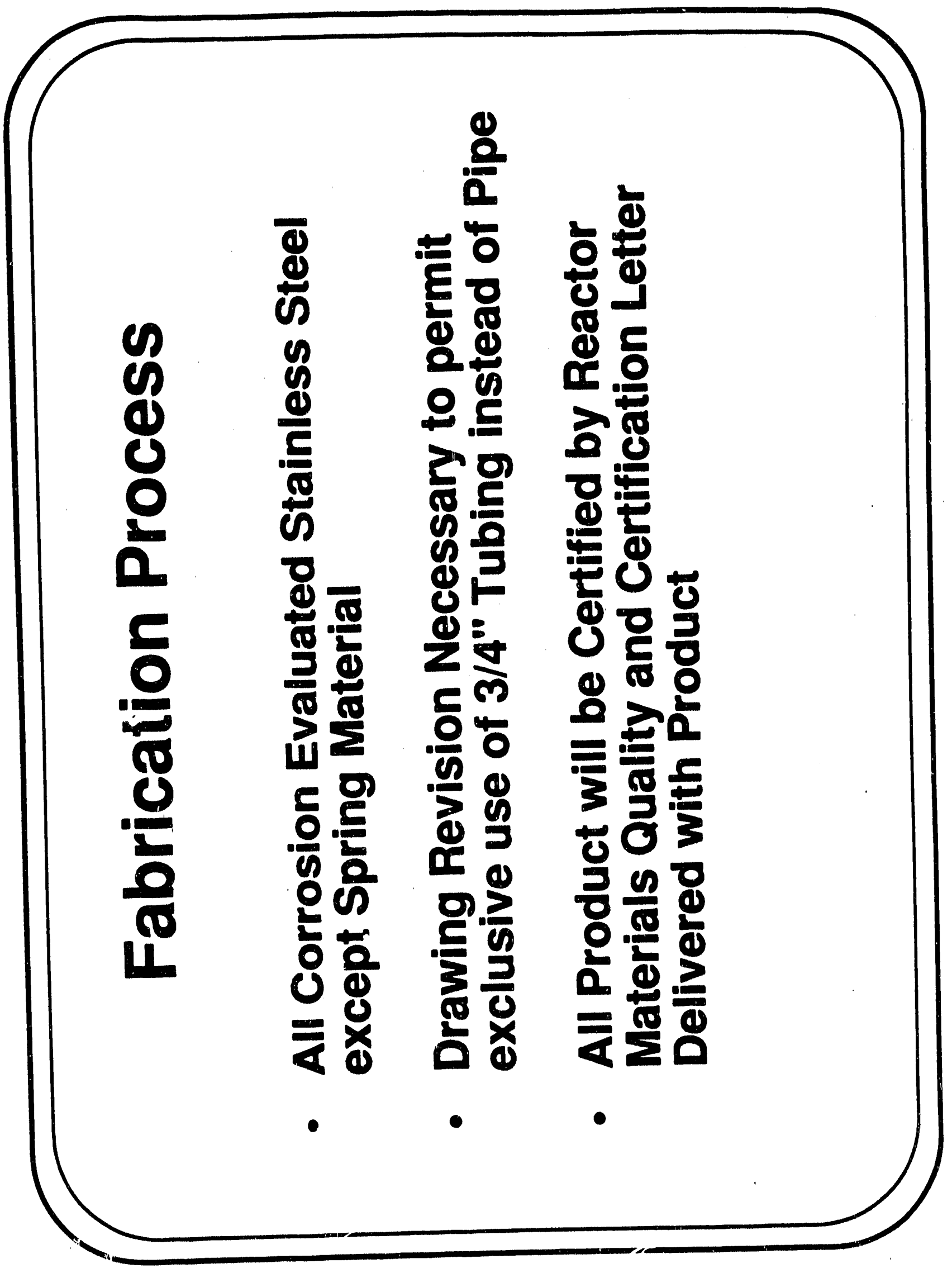




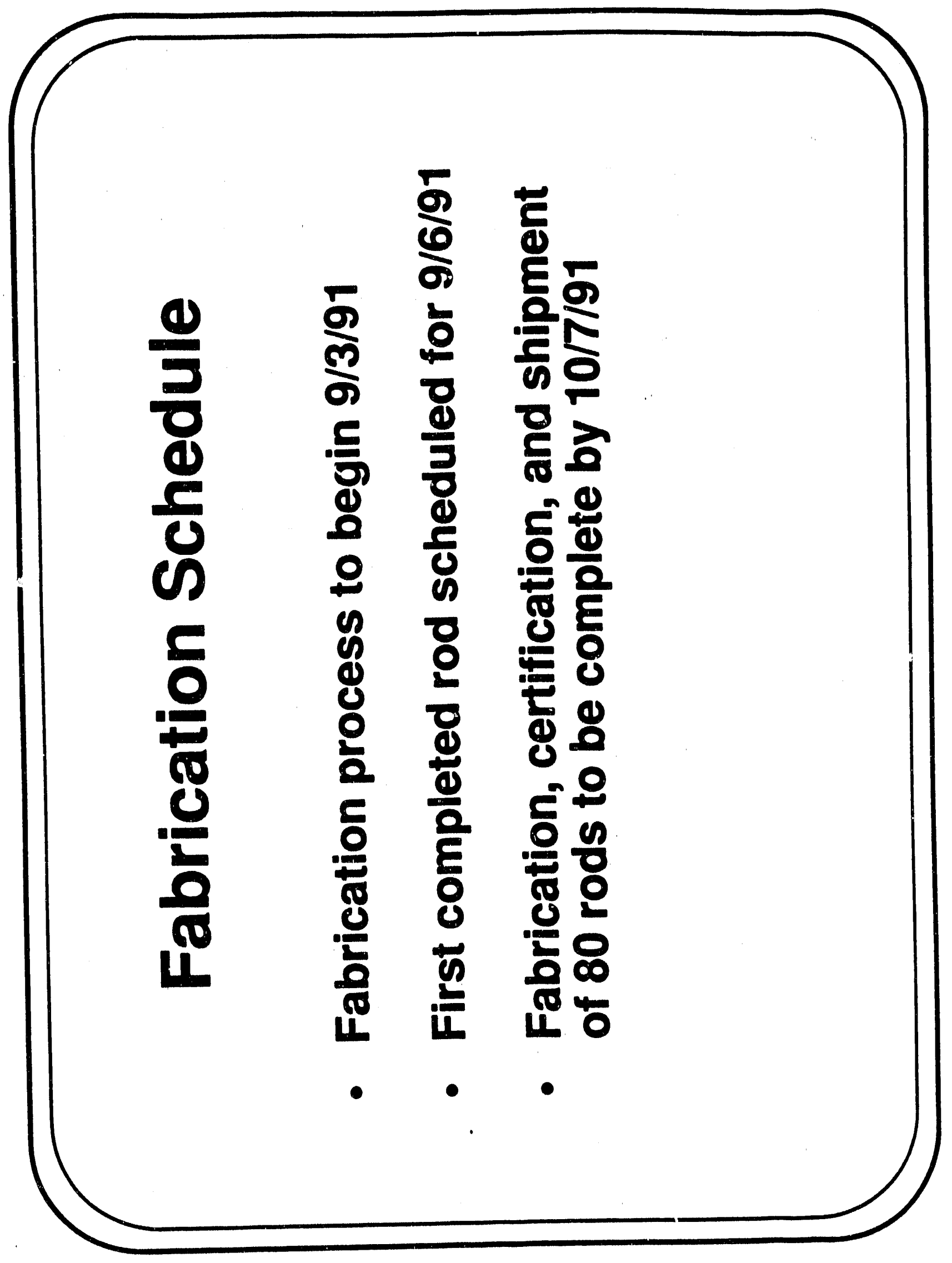




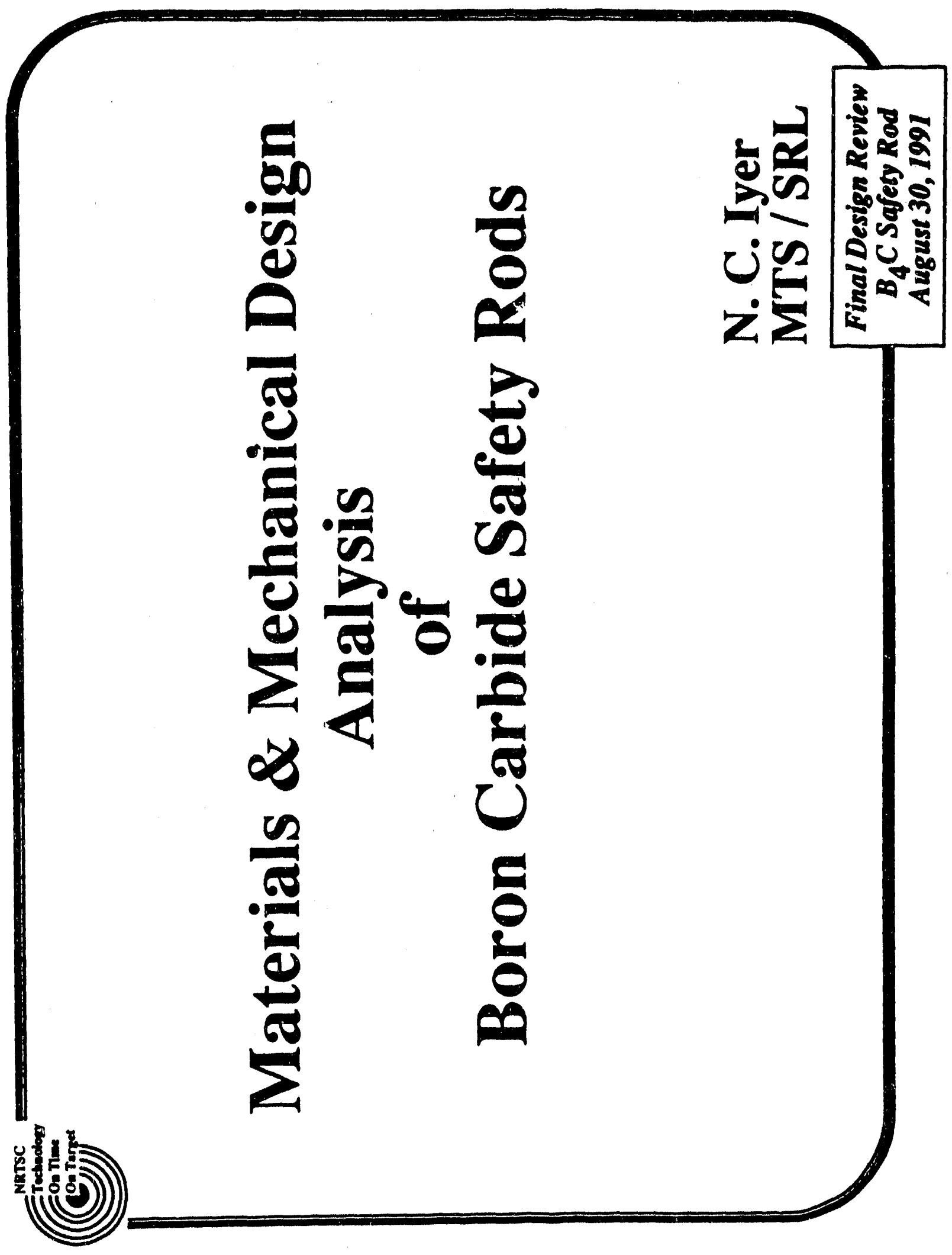




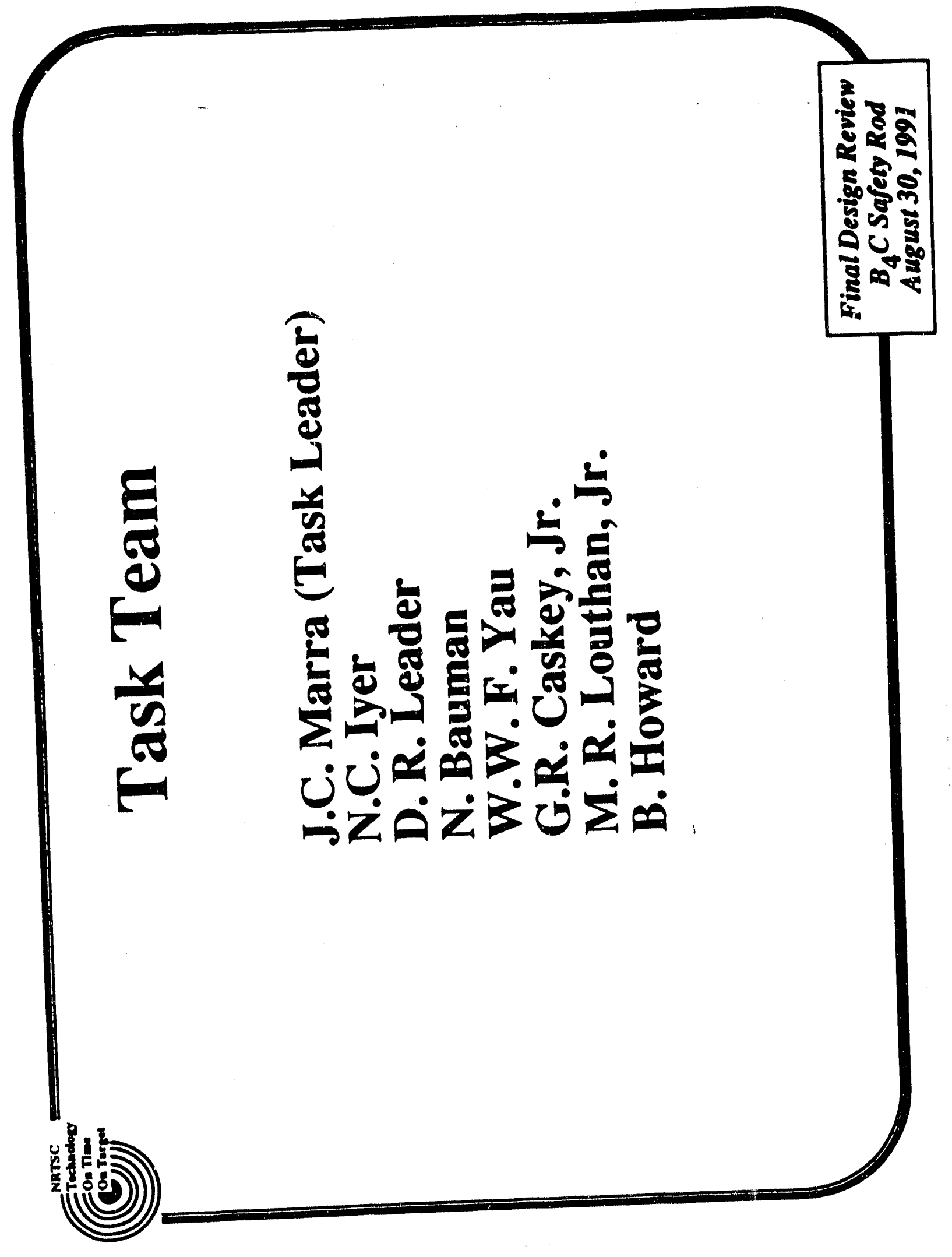




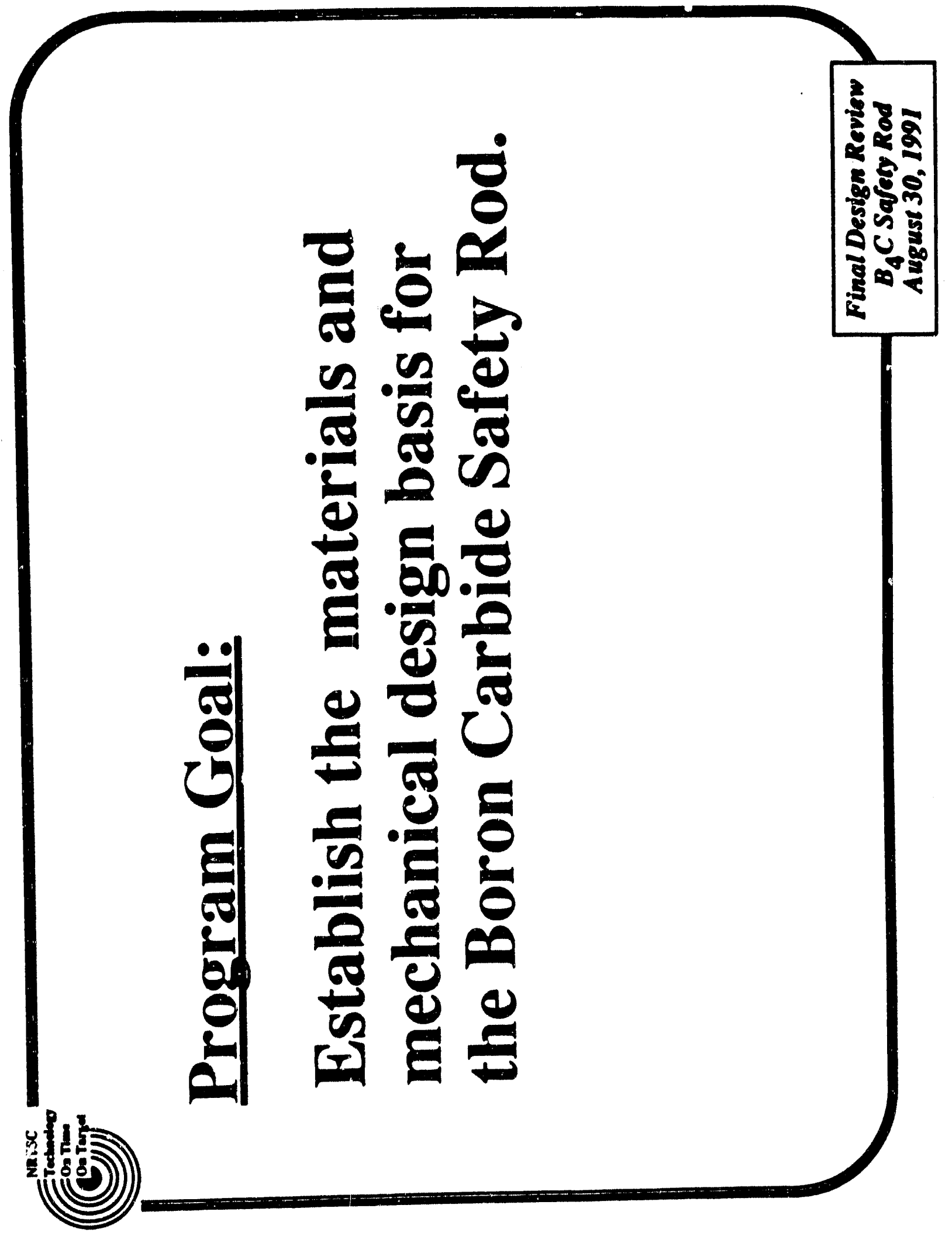




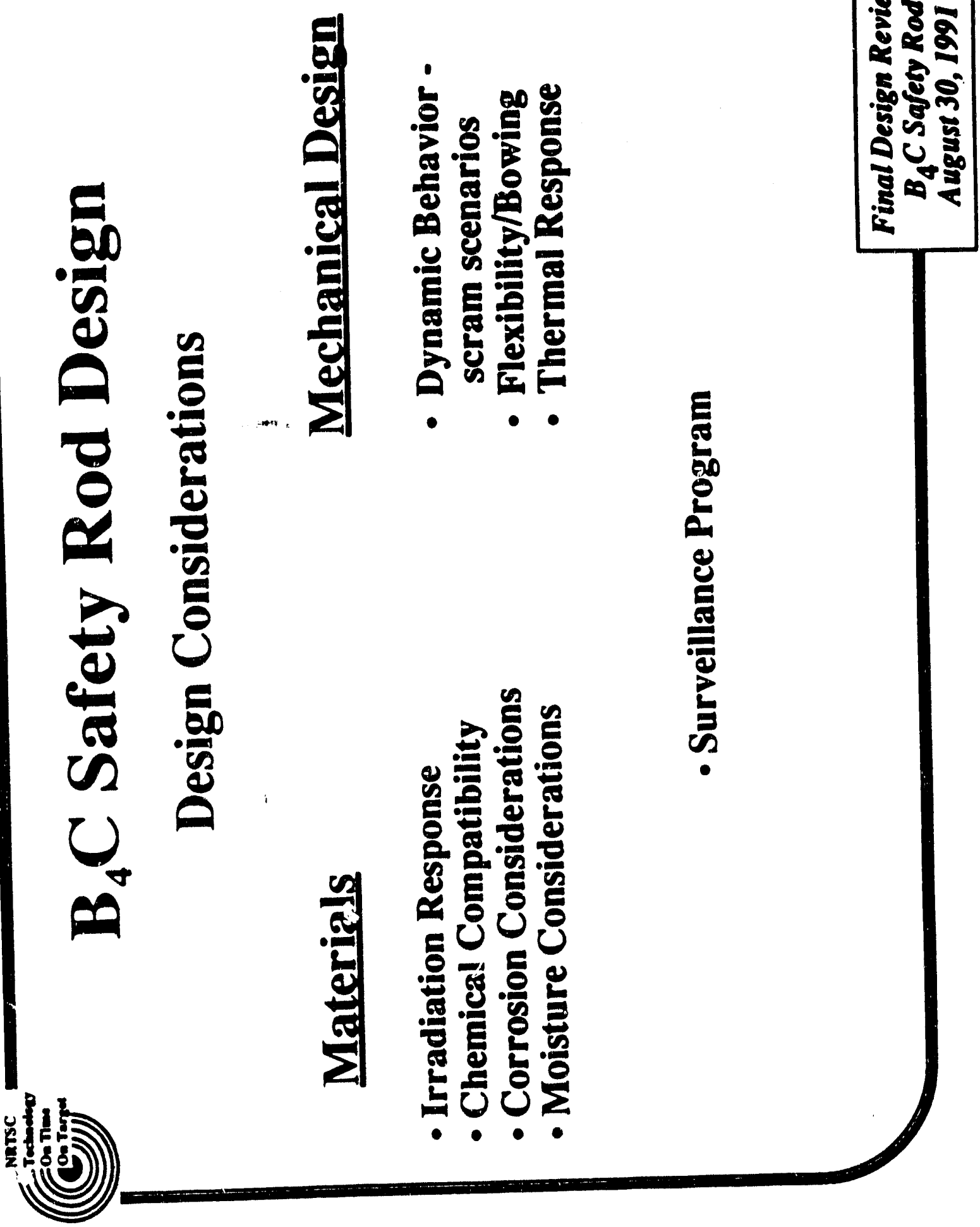




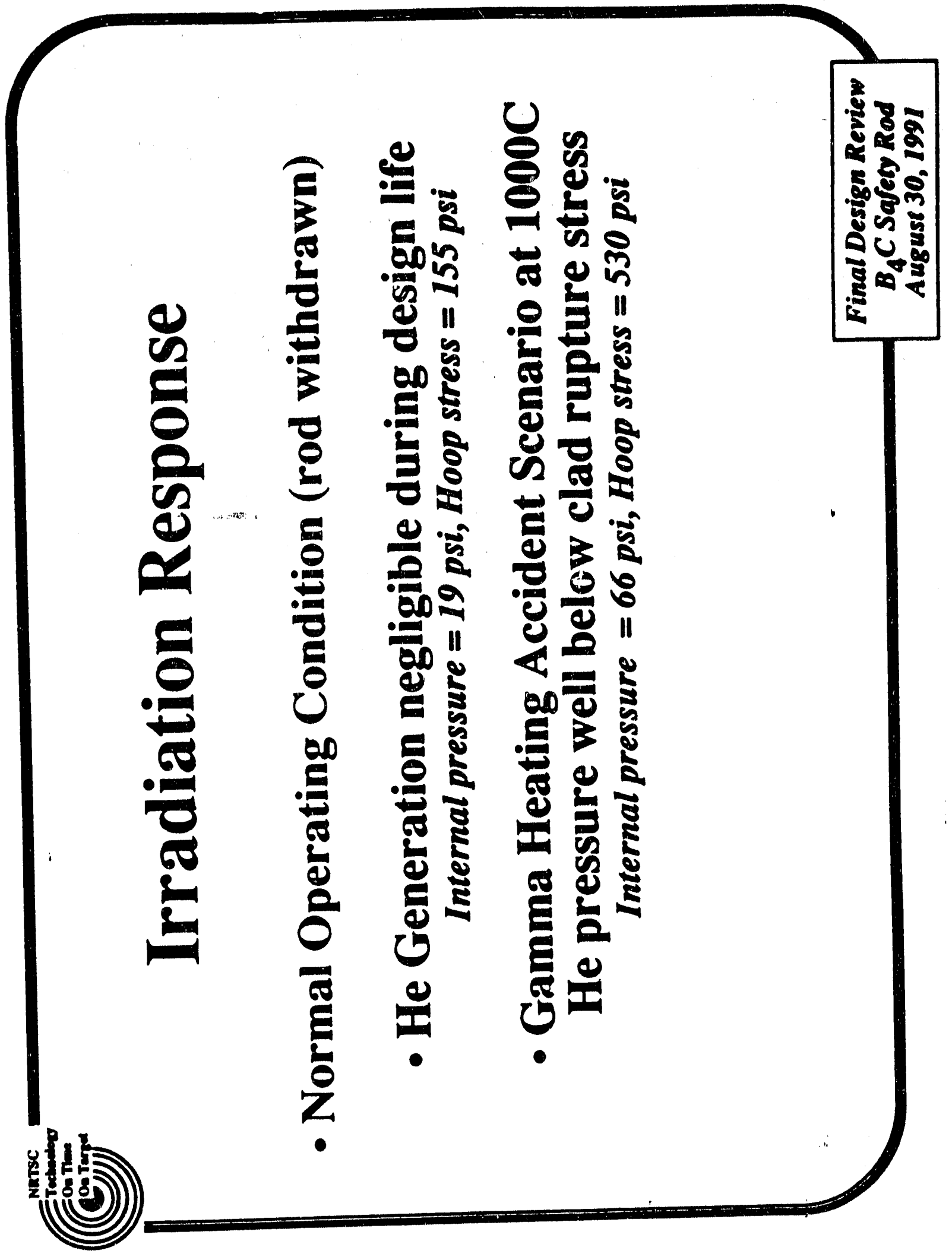




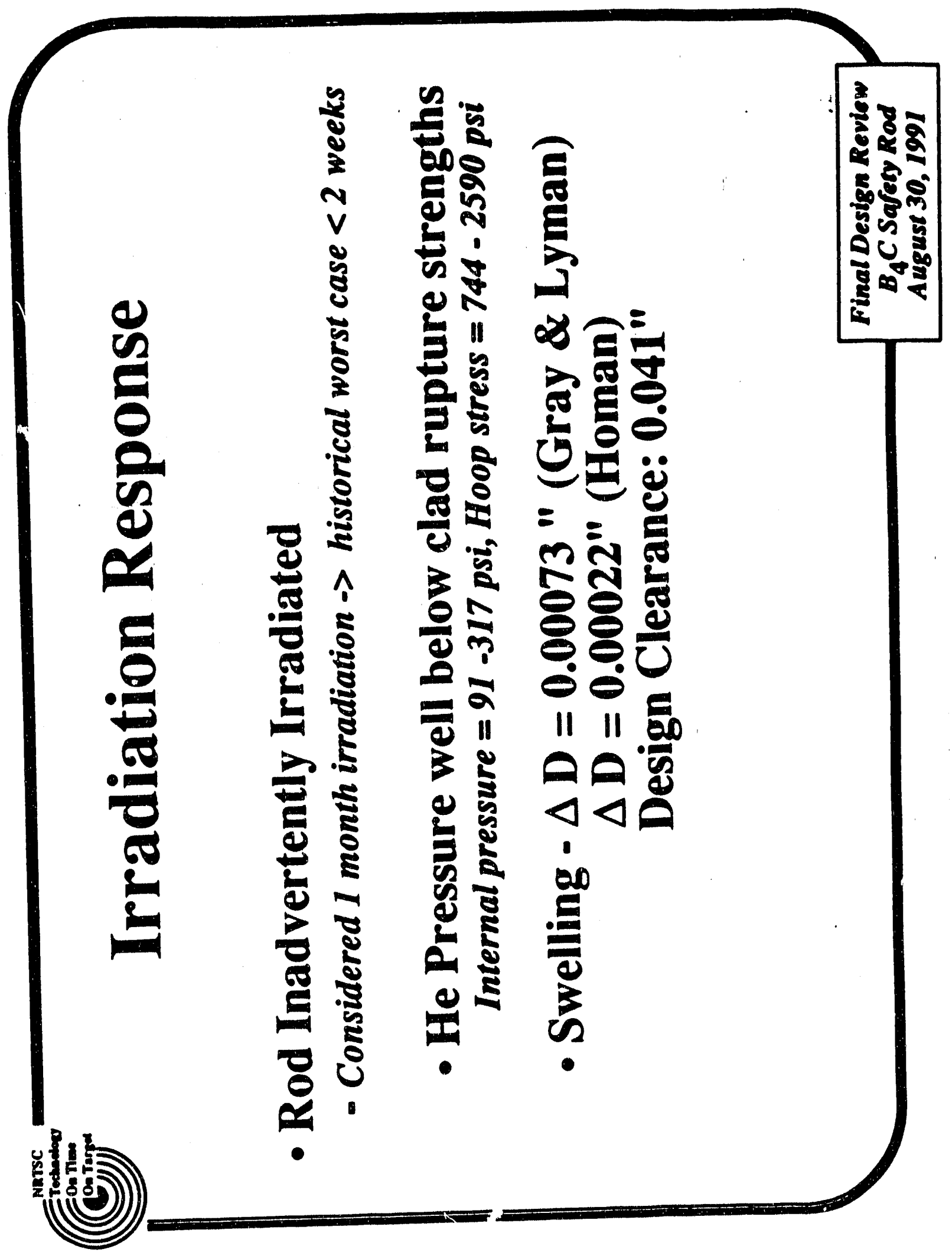




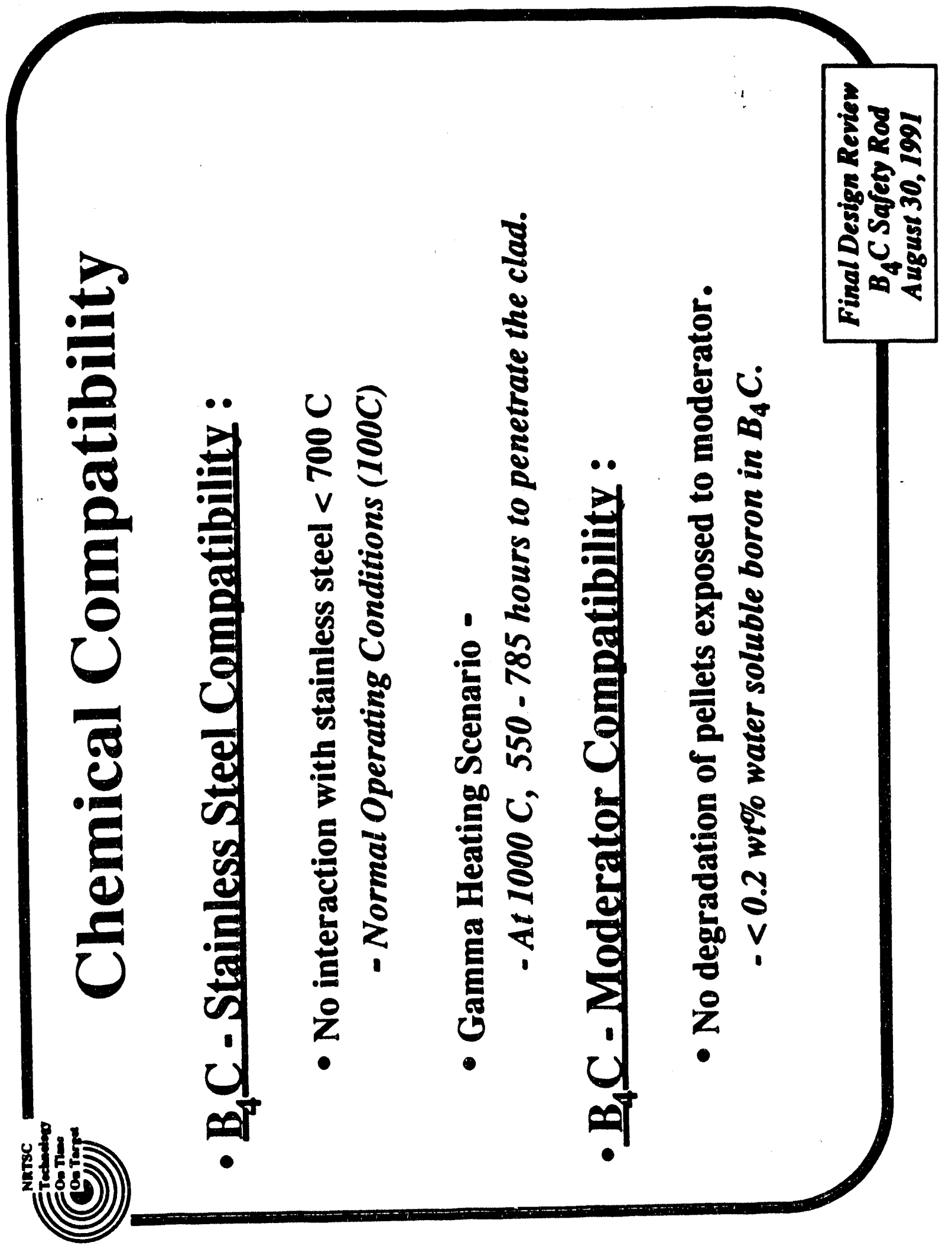




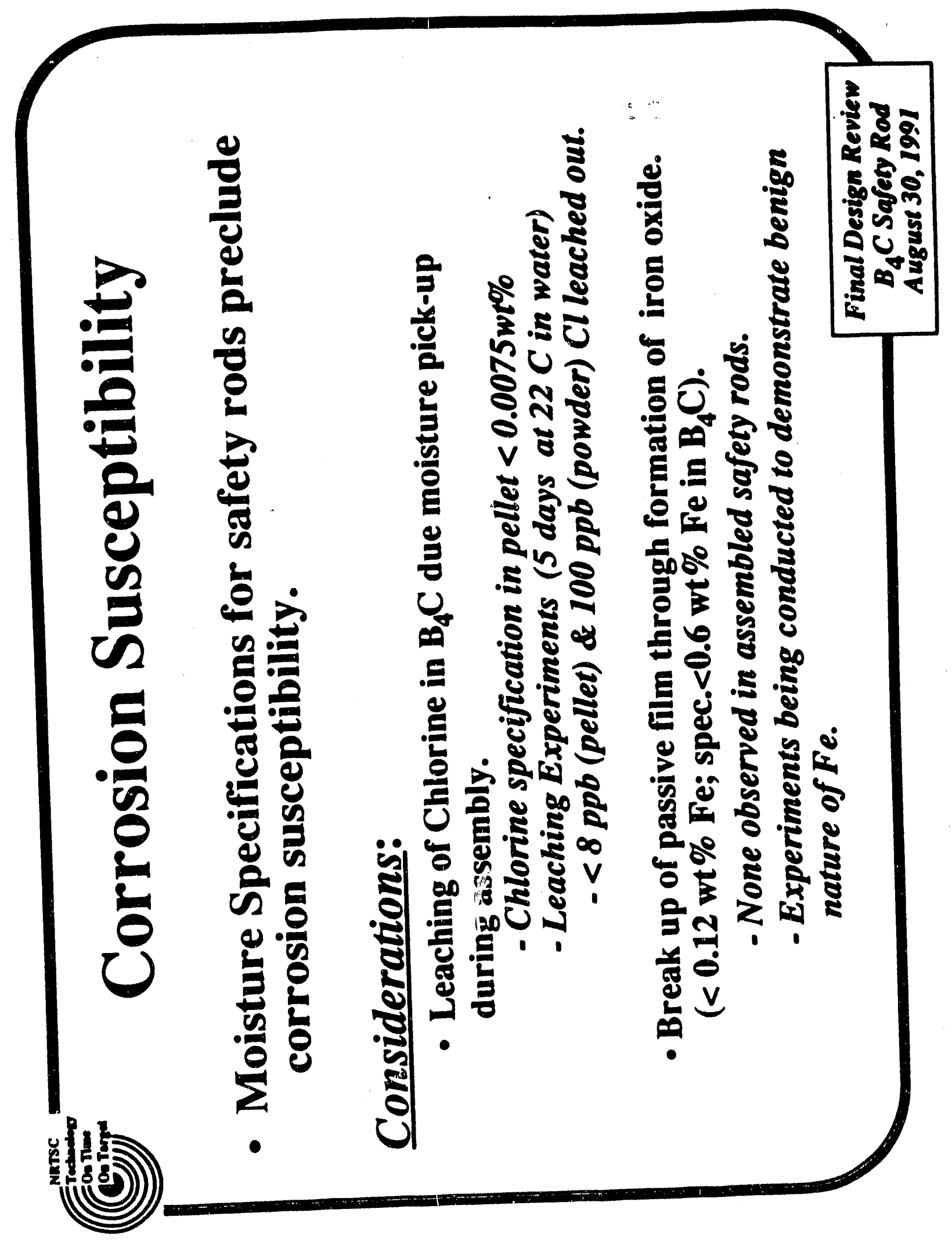




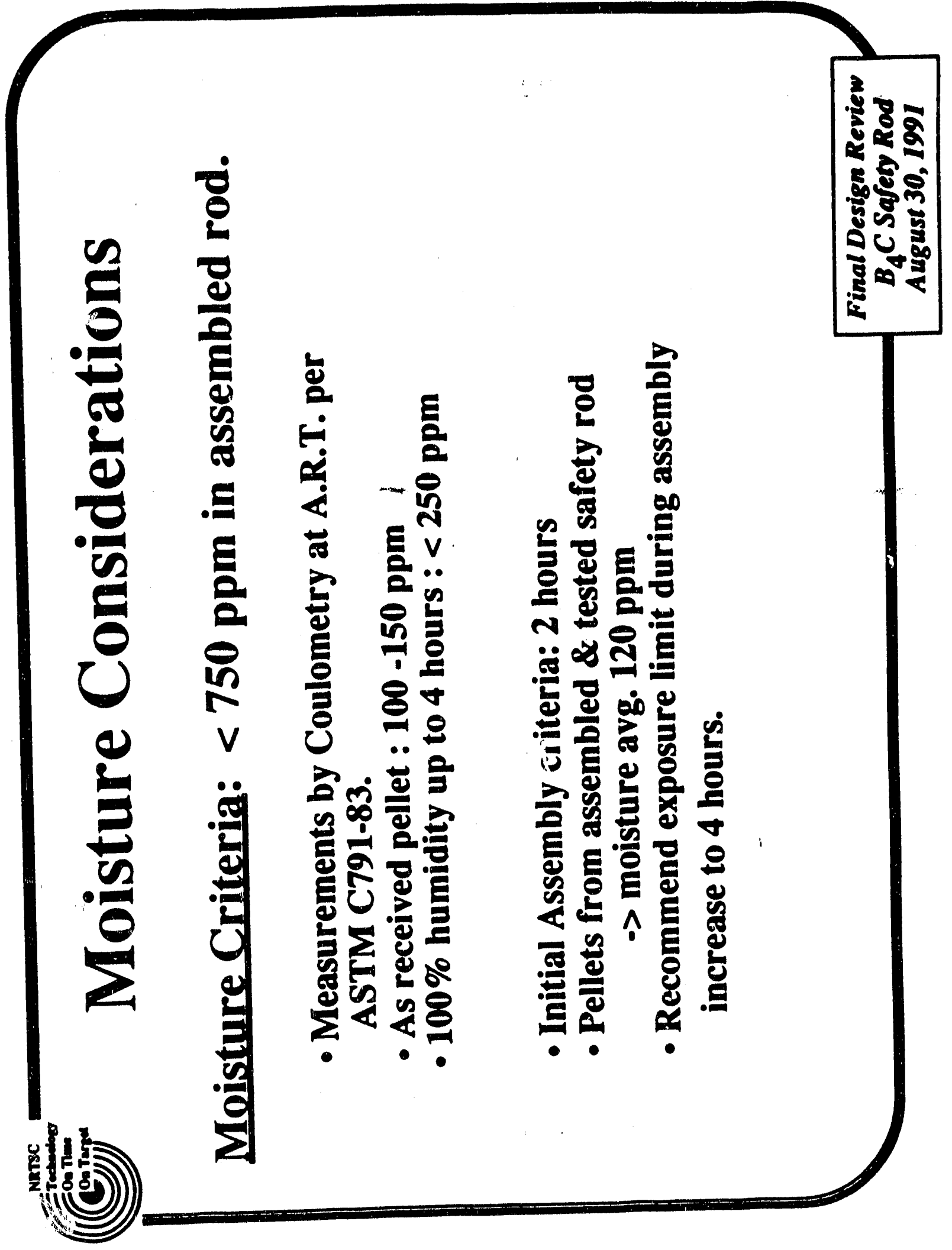




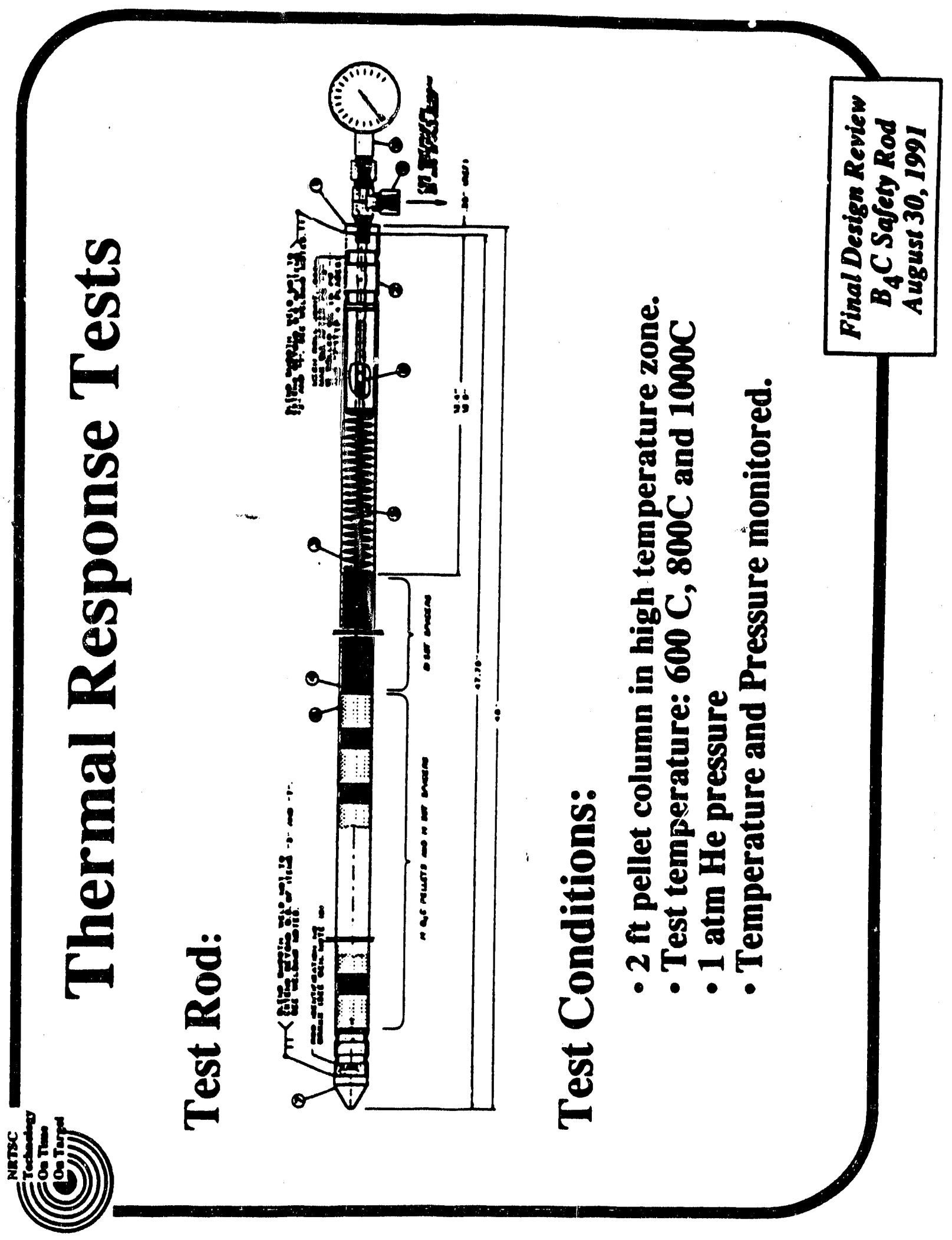




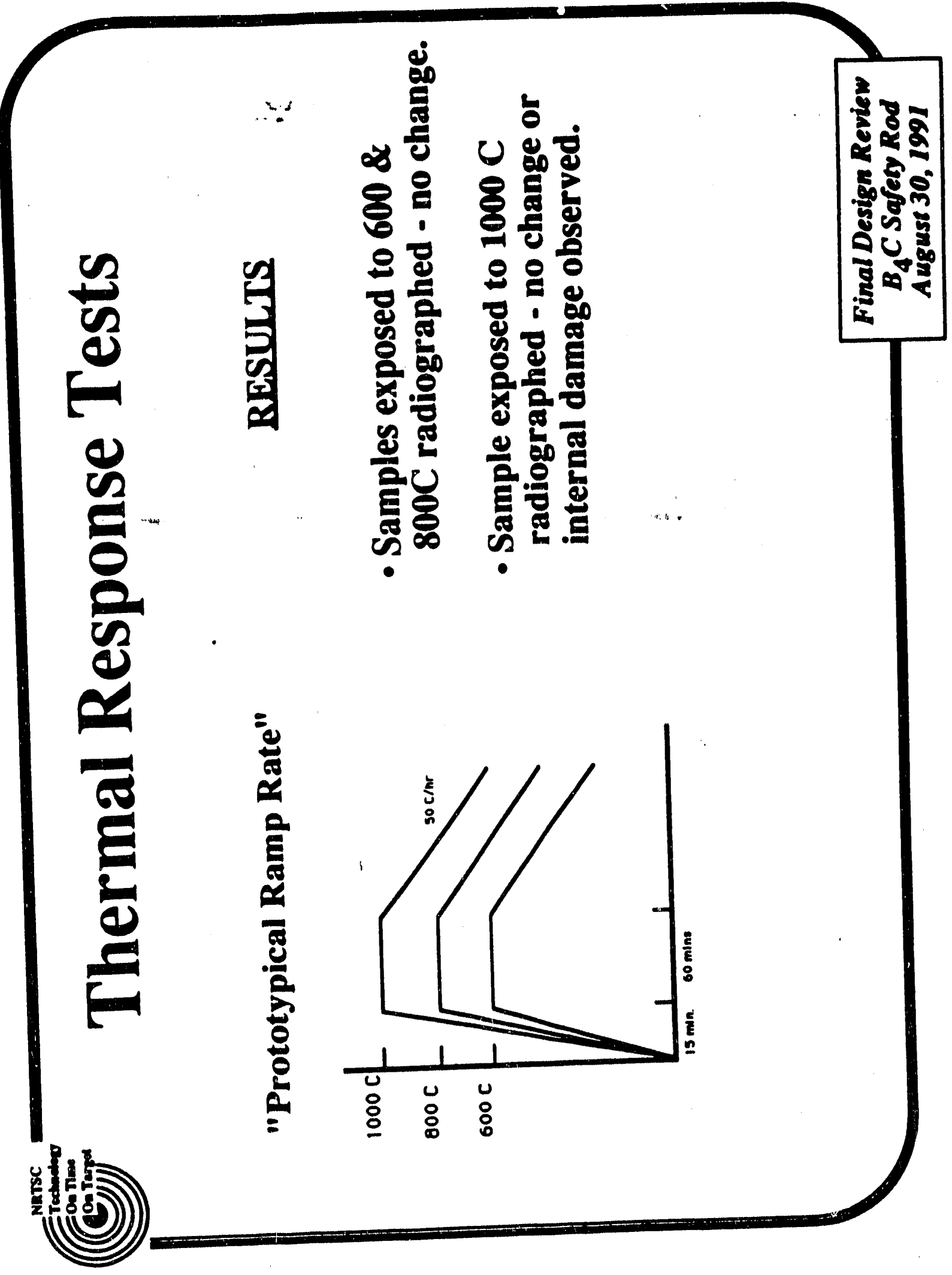




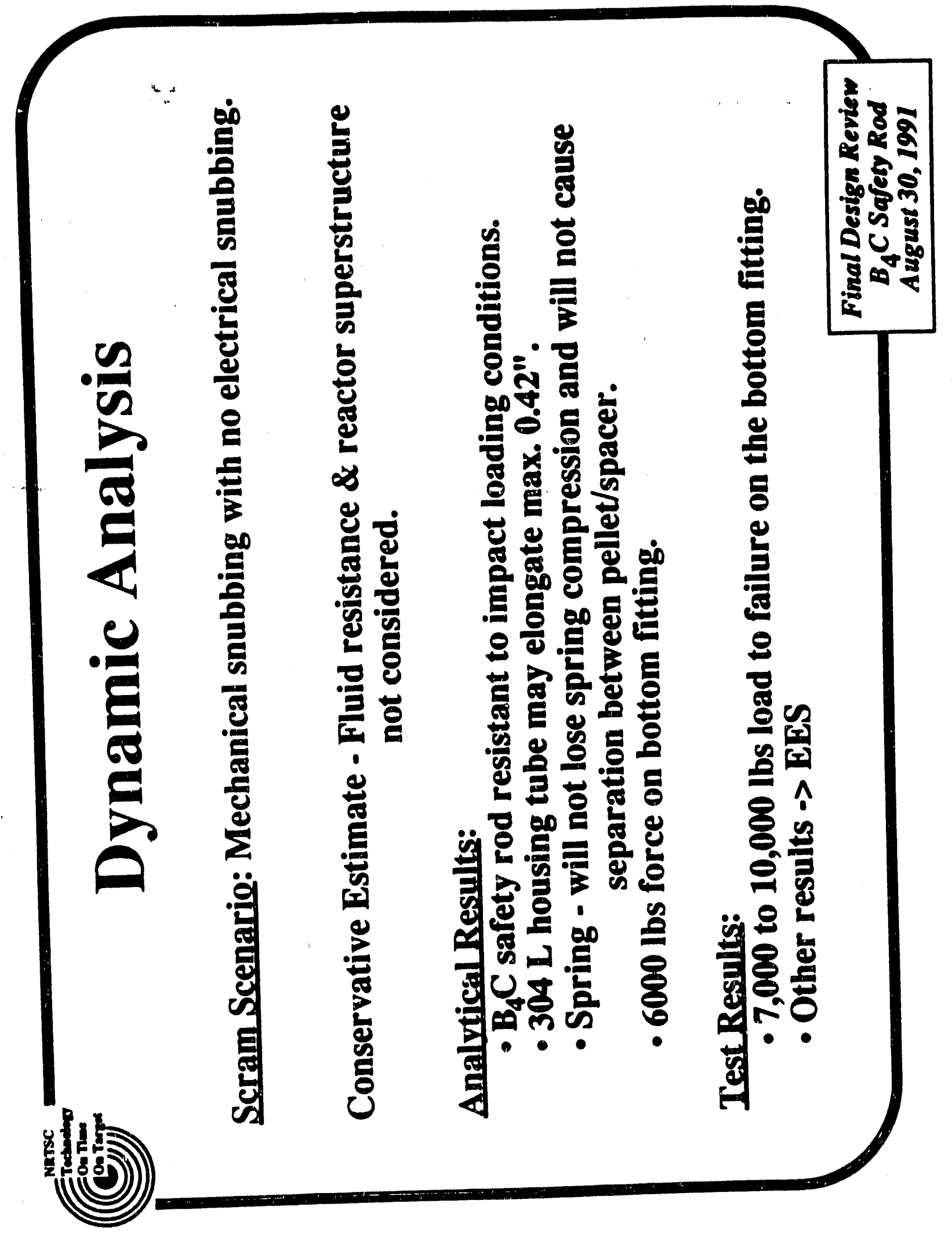




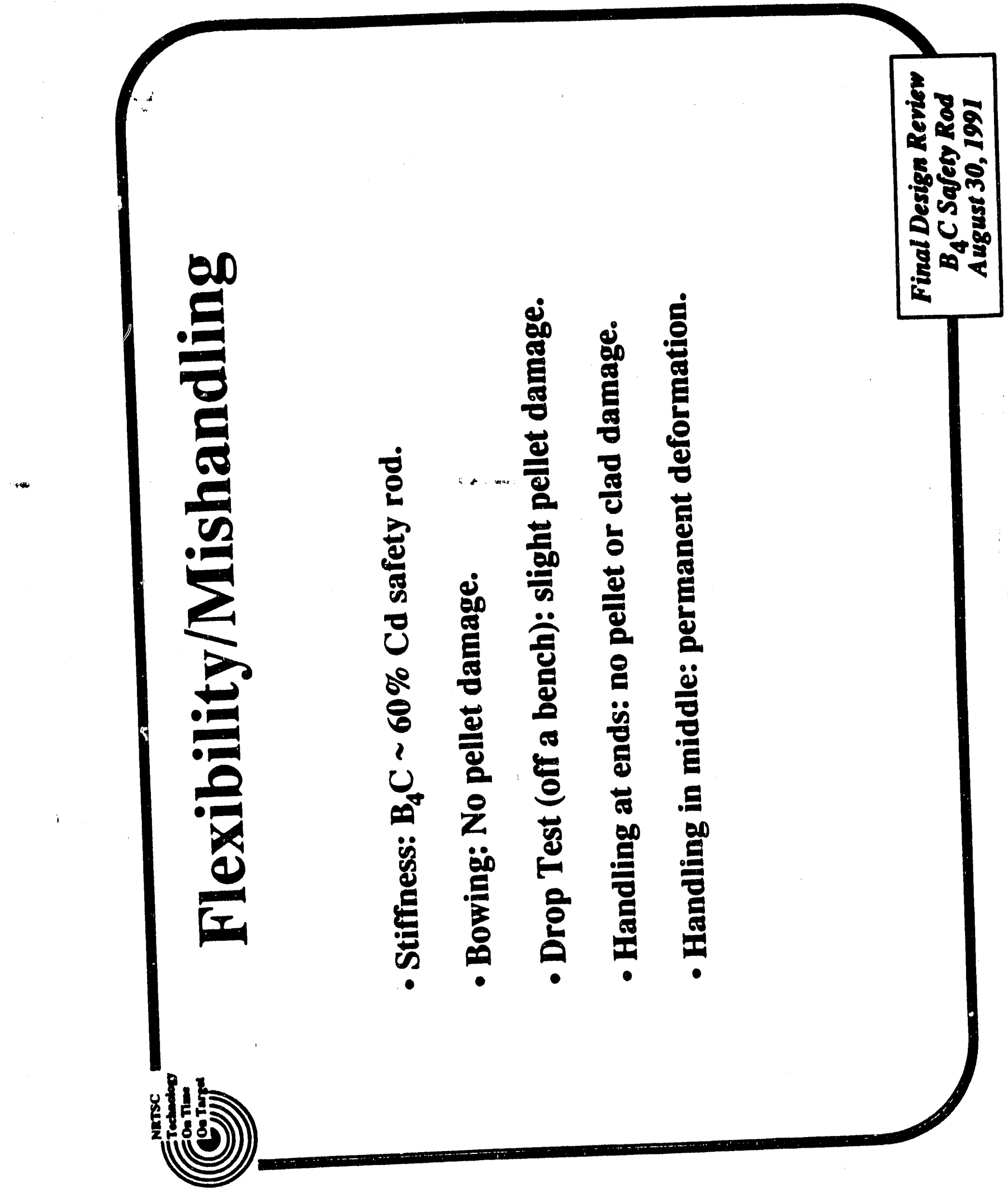




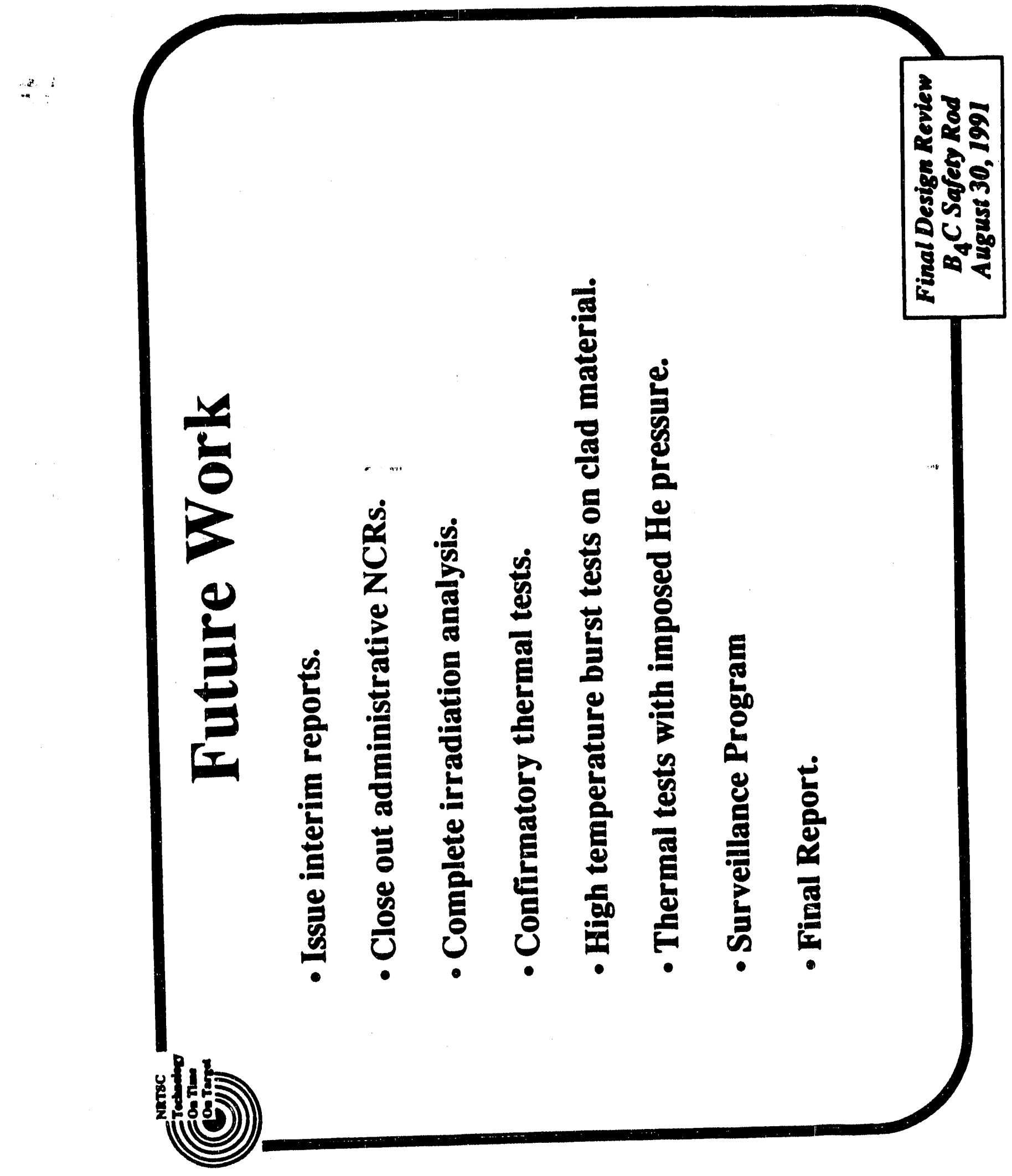




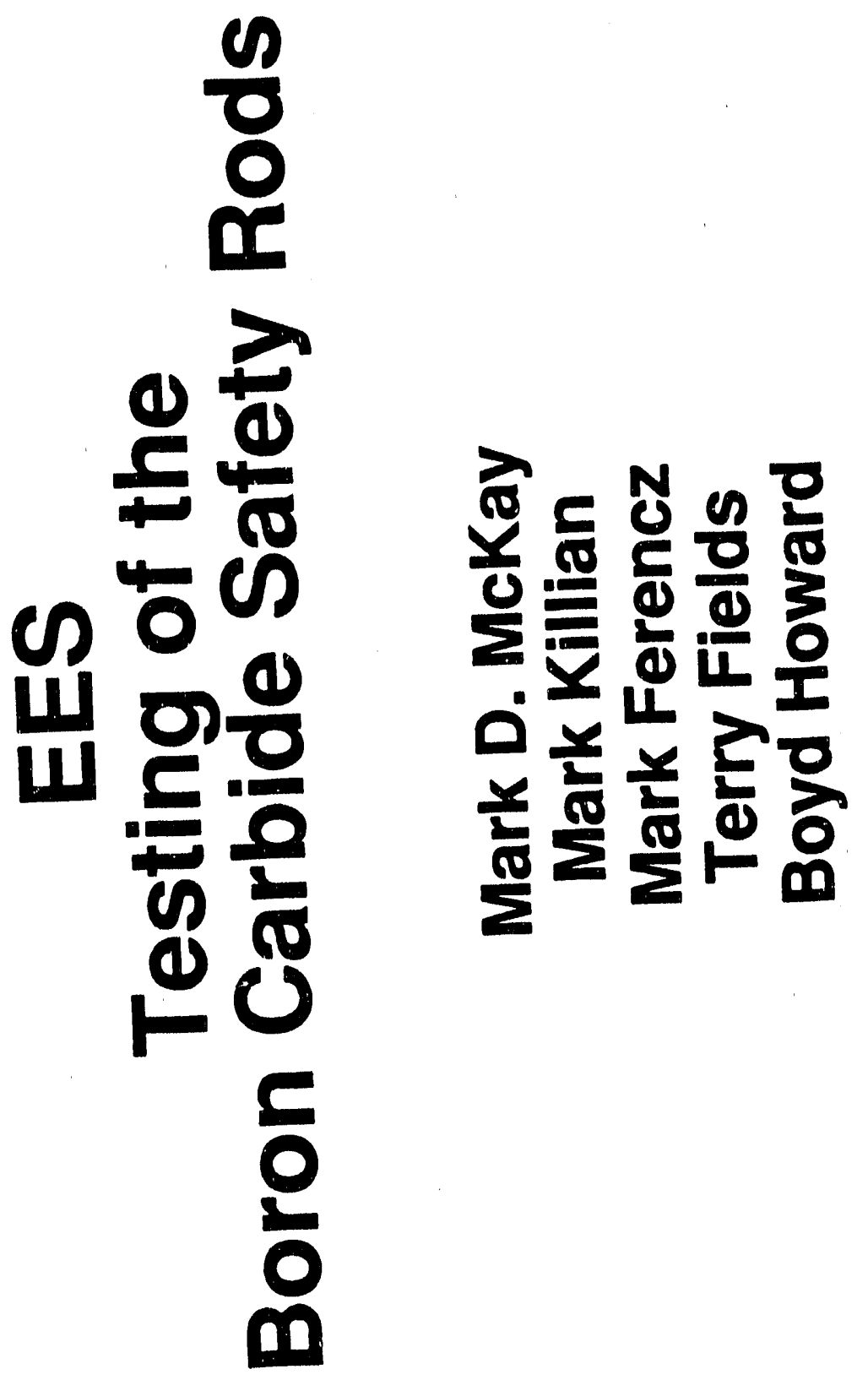



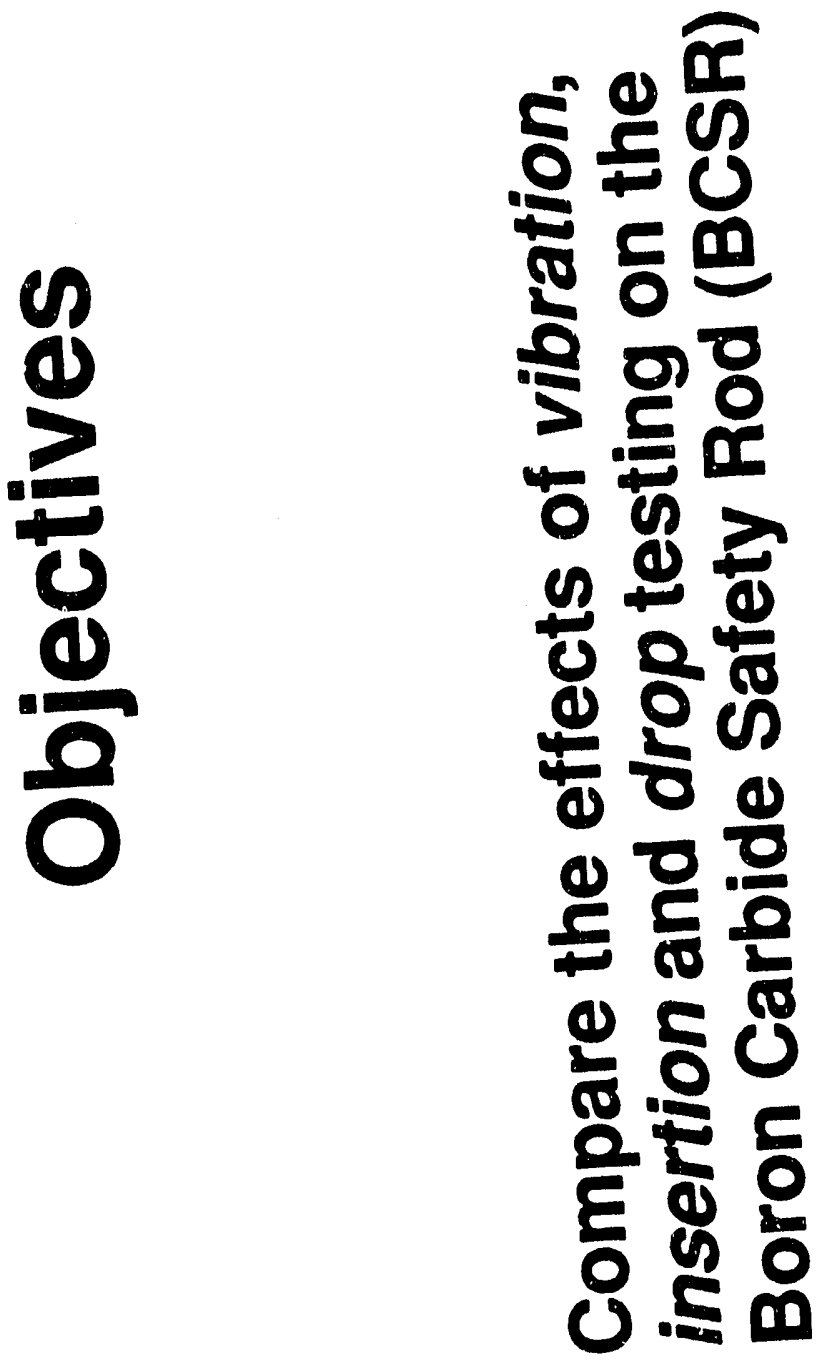


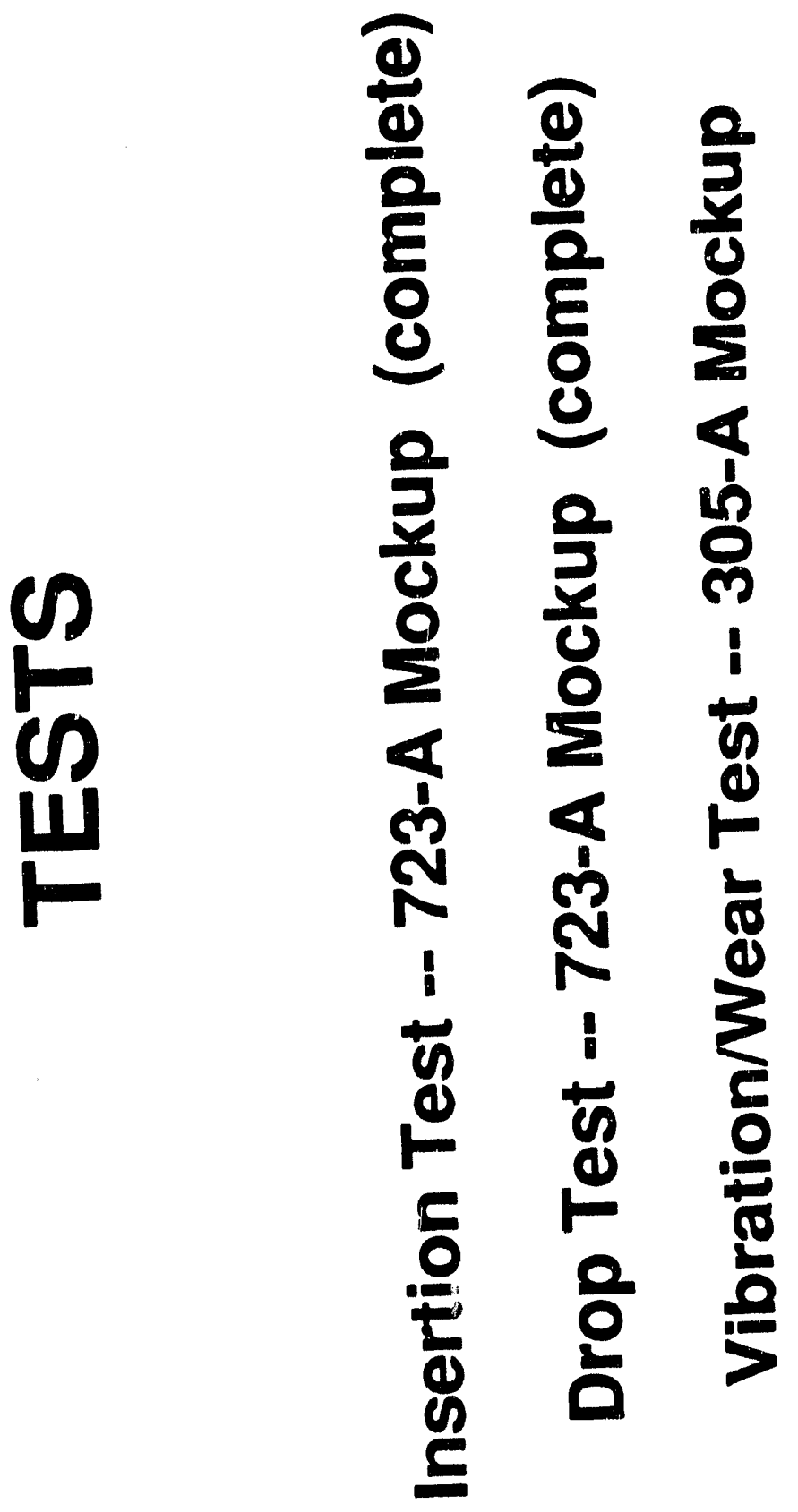




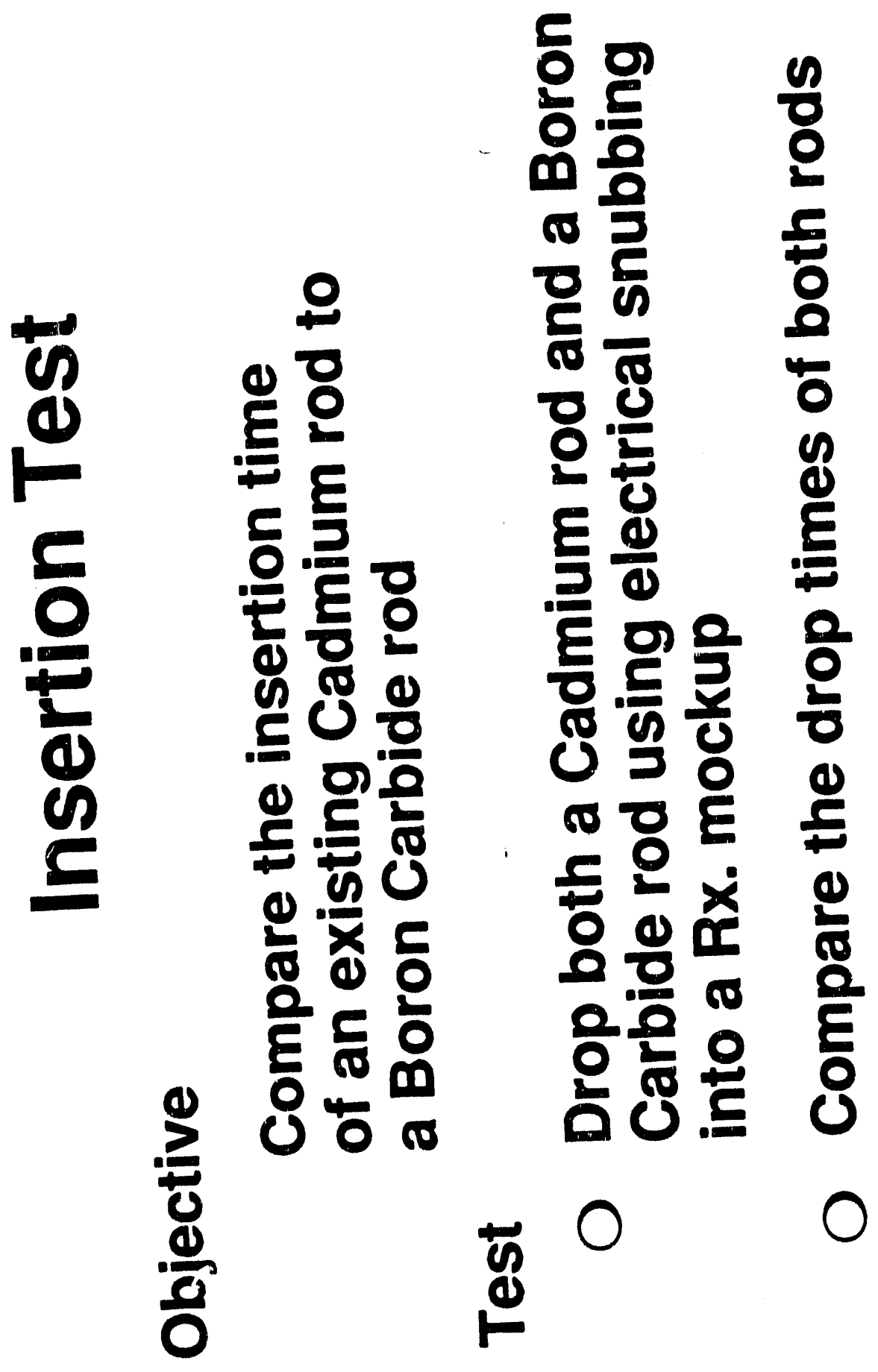




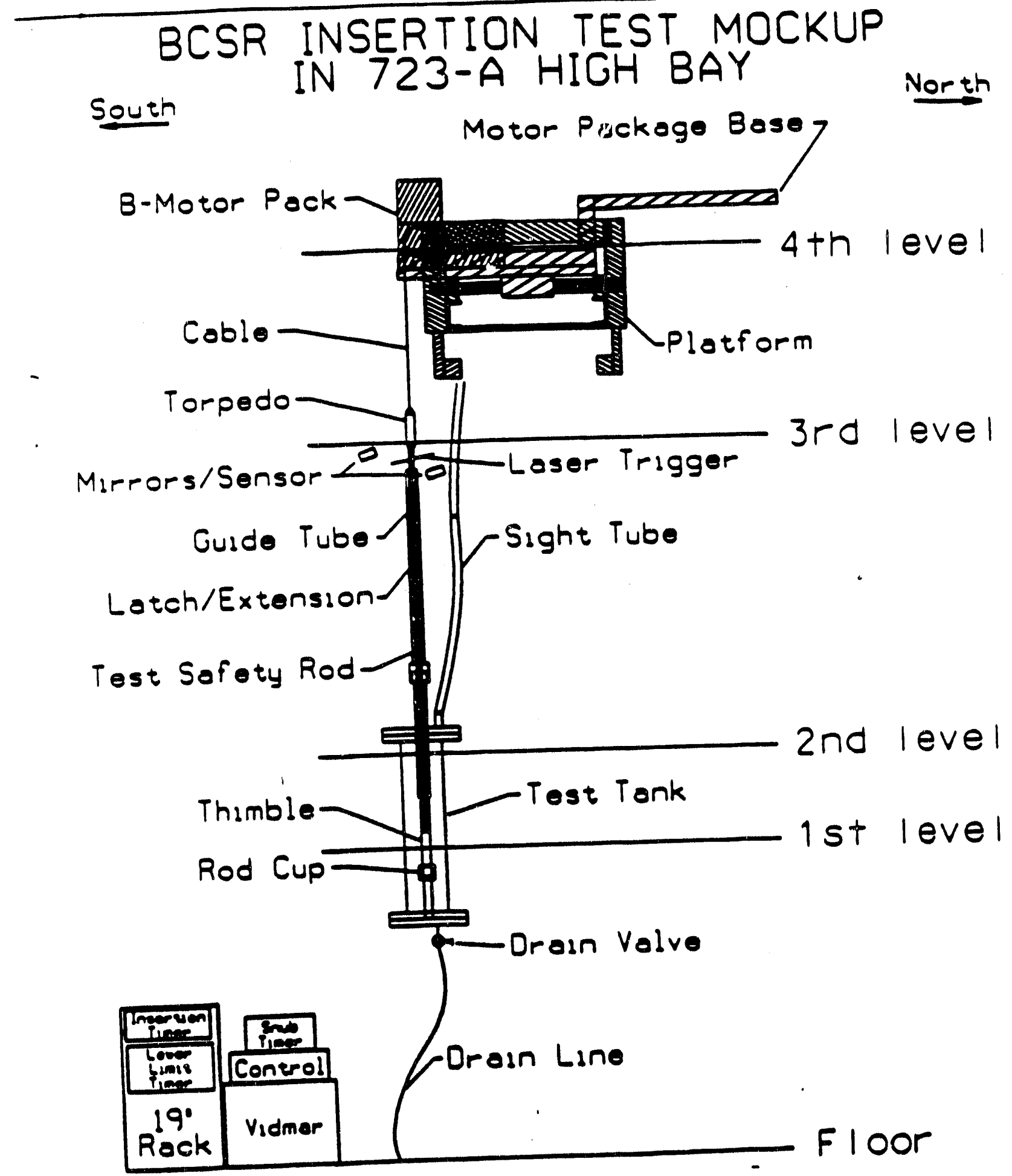




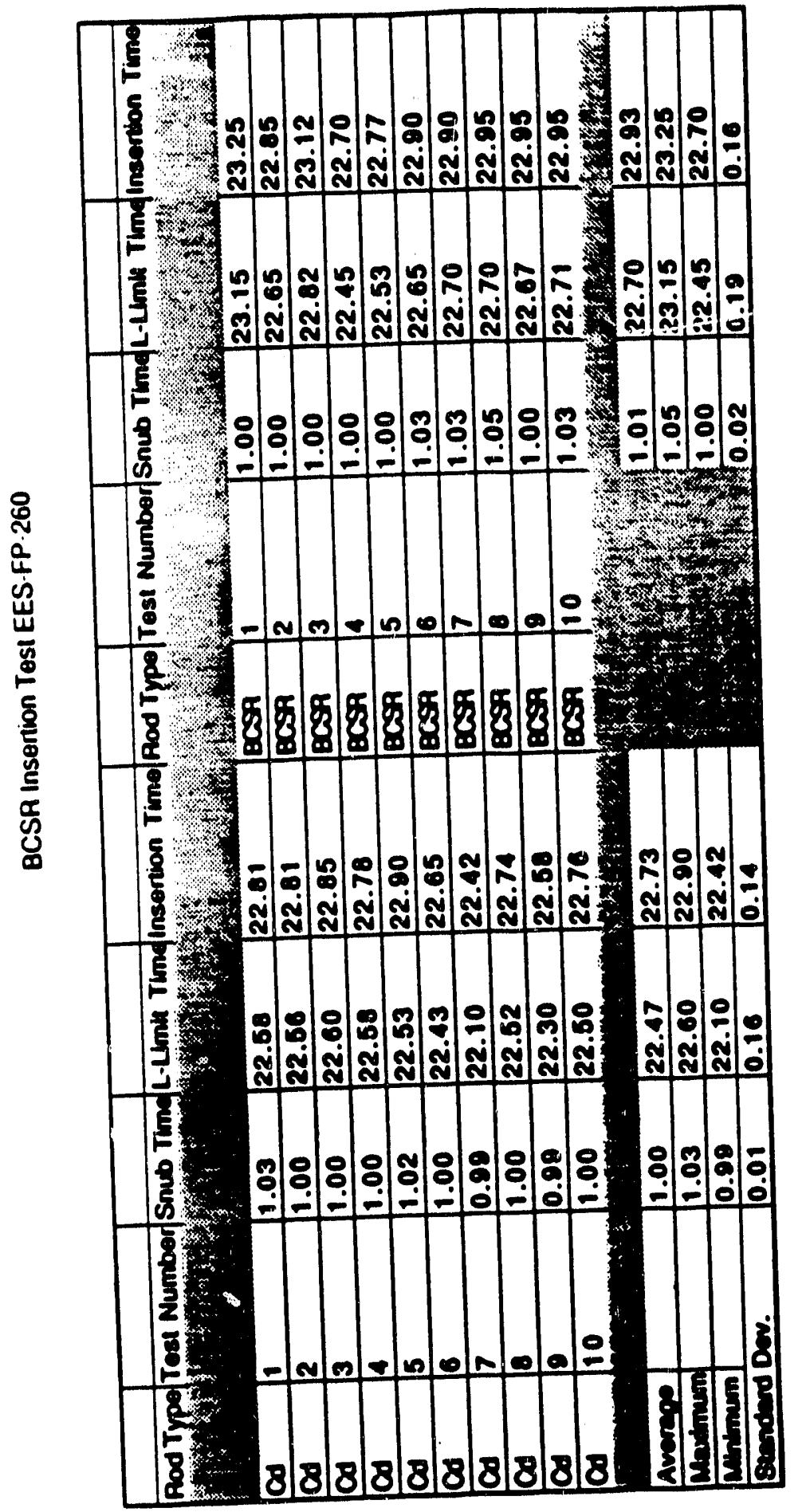




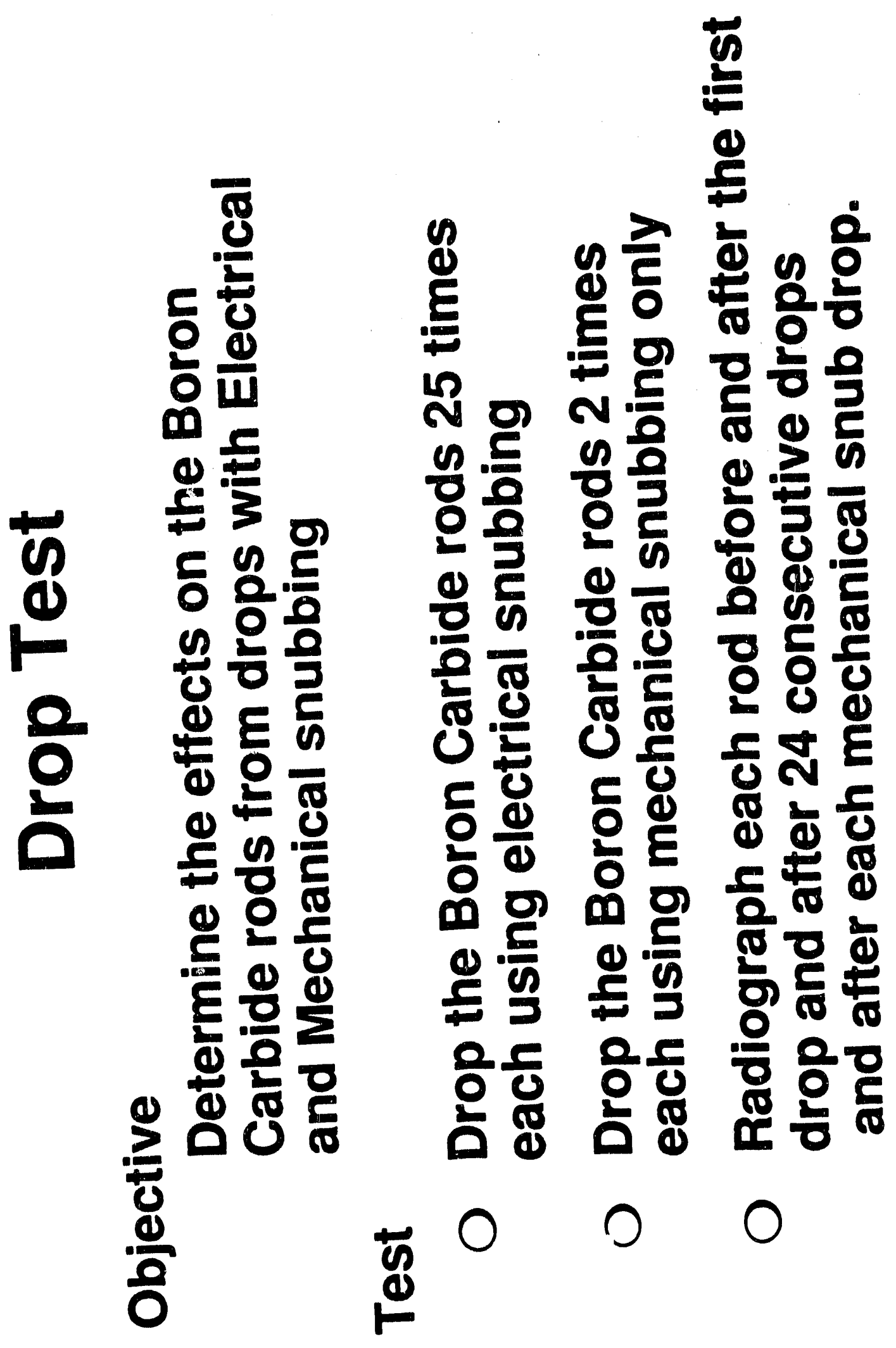




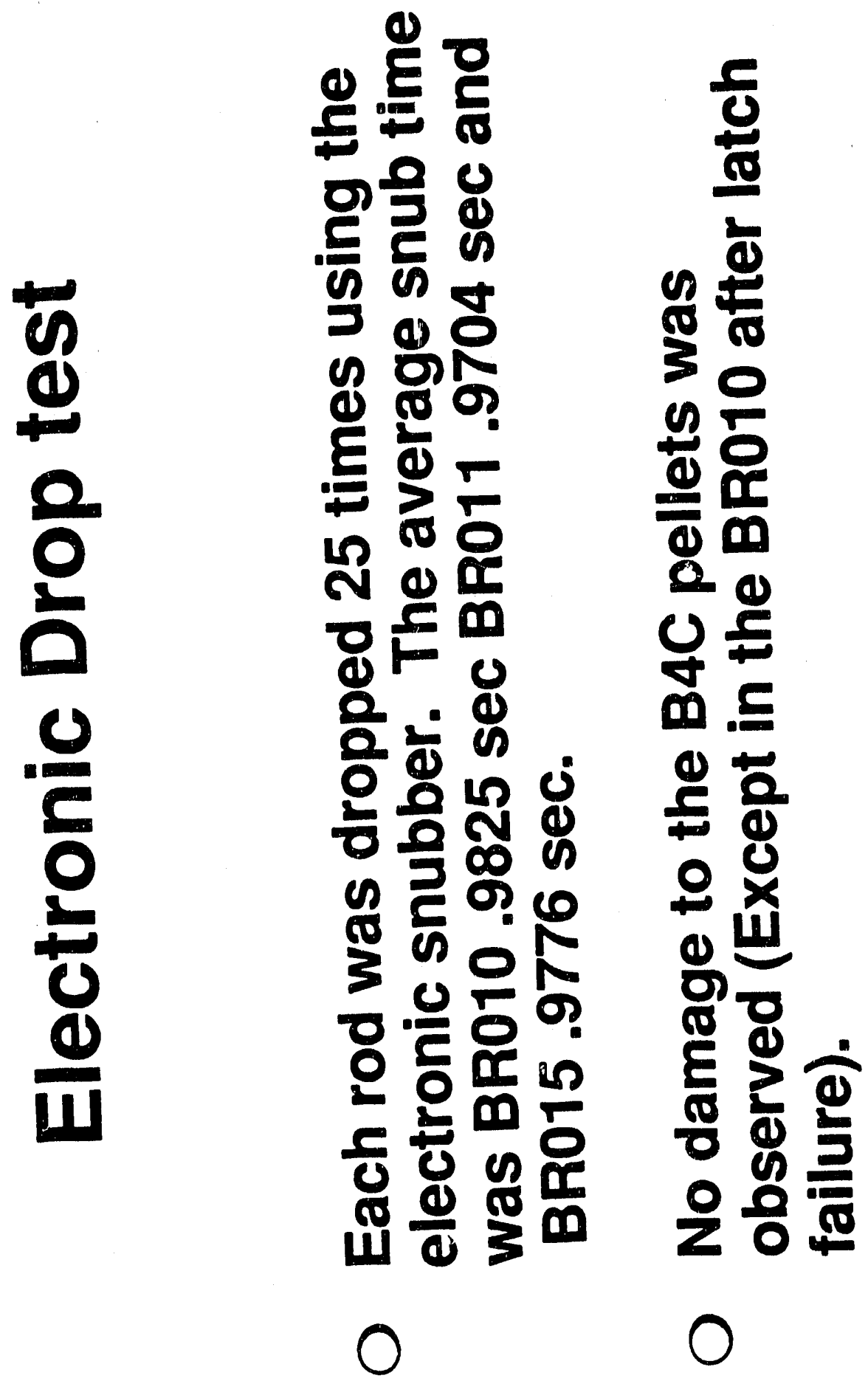




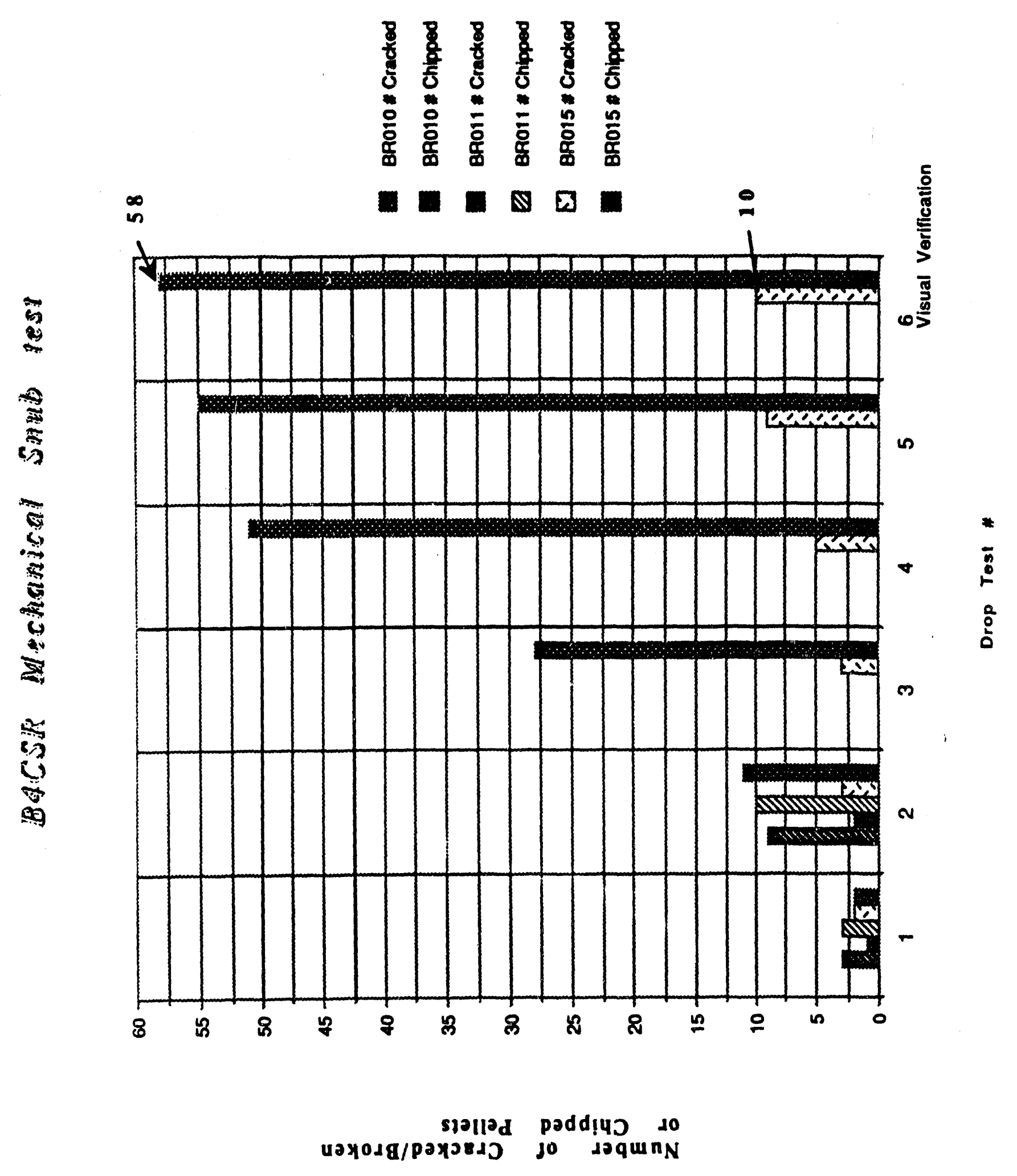




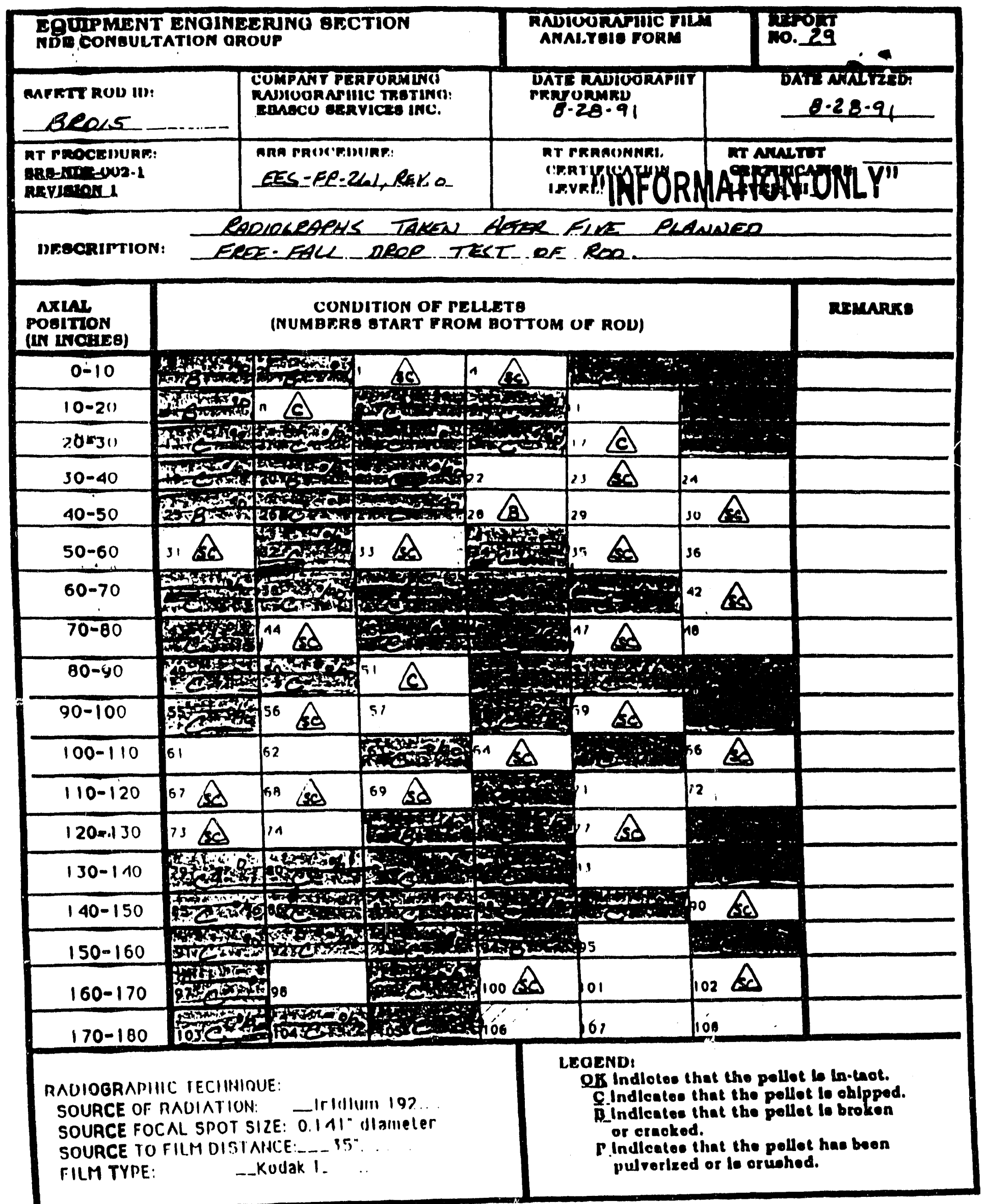




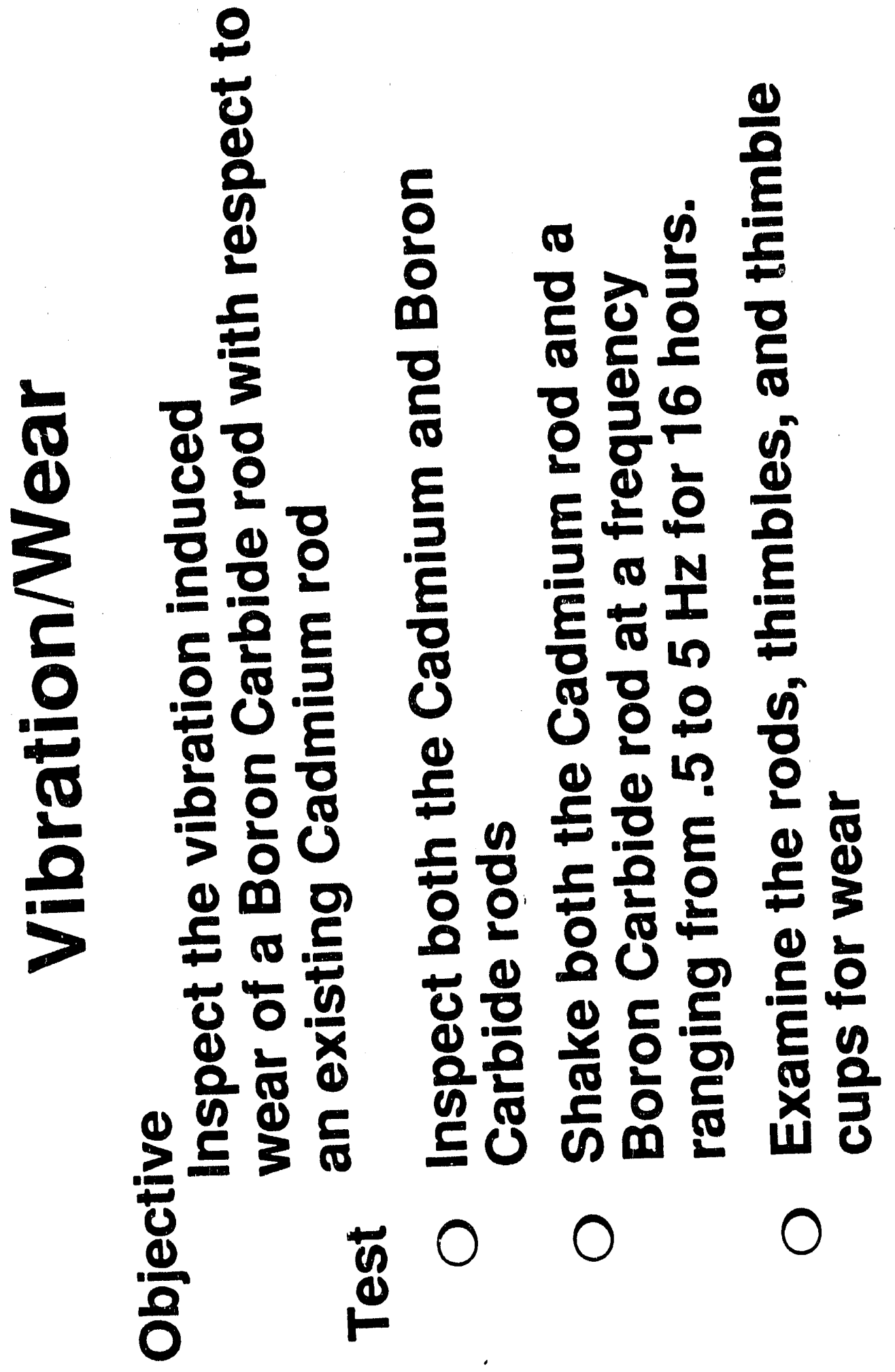




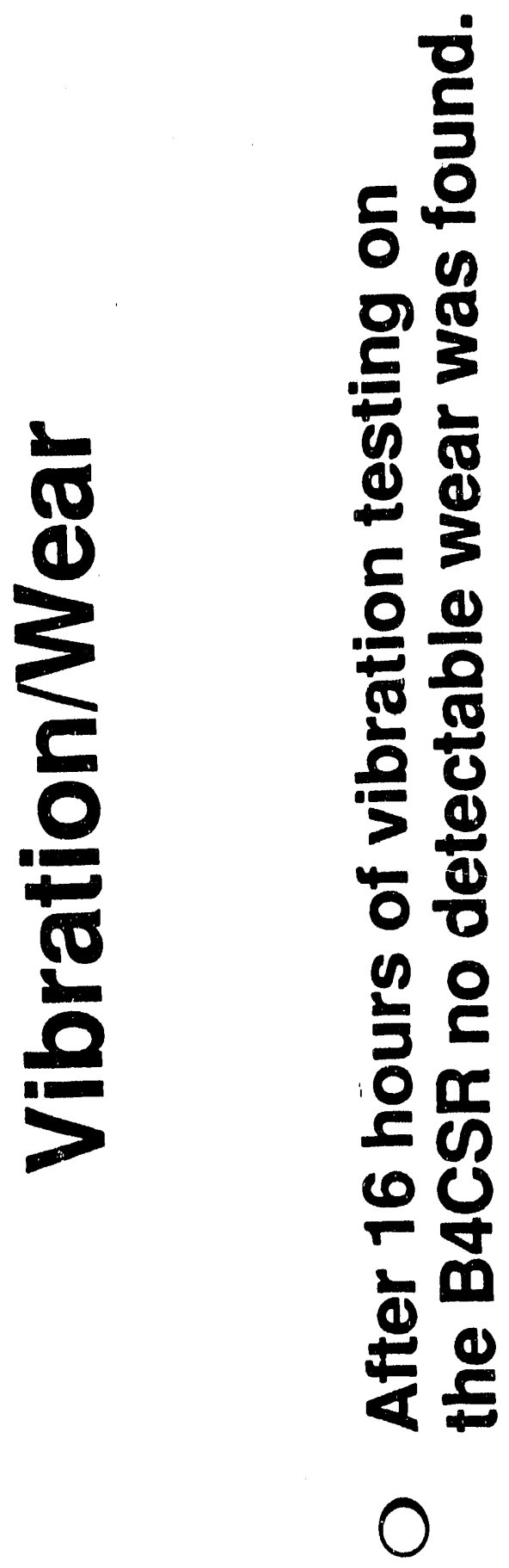




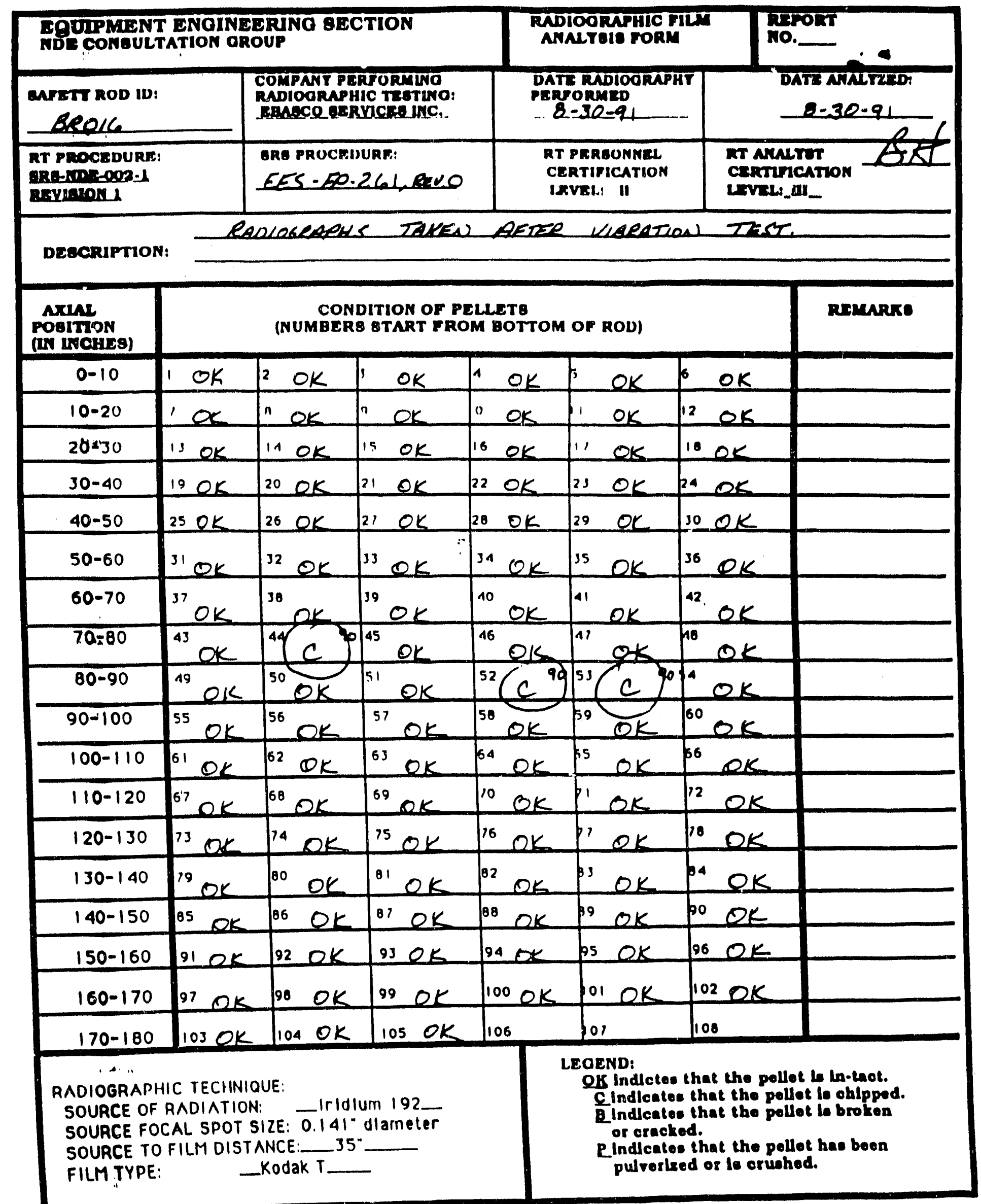



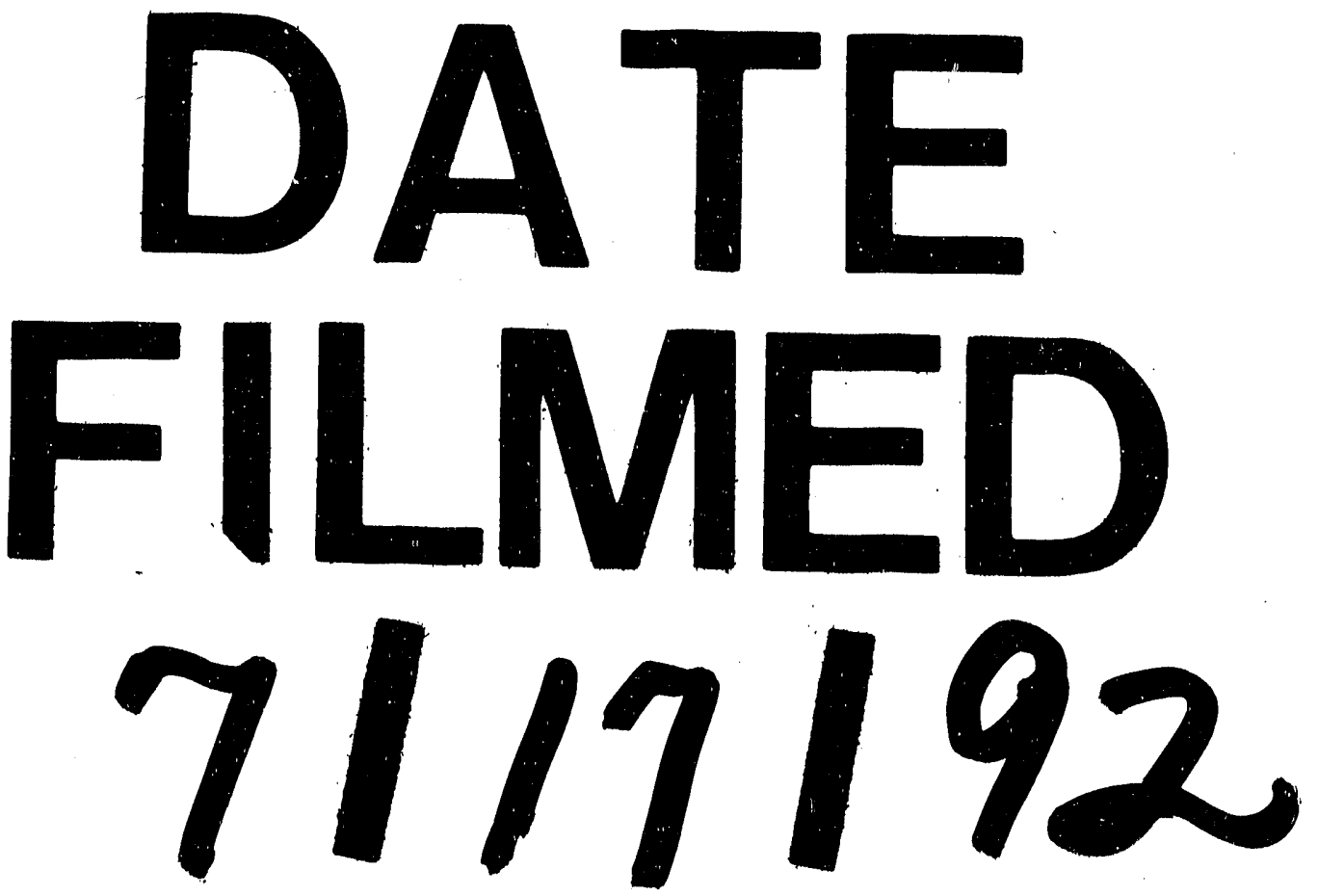
